\title{
Evolving therapeutic landscape in follicular lymphoma: a look at emerging and investigational therapies
}

\author{
Walter Hanel ${ }^{1}$ and Narendranath Epperla ${ }^{1,2^{*}}$ (1)
}

\begin{abstract}
Follicular Lymphoma (FL) is the most common subtype of indolent B cell non-Hodgkin lymphoma. The clinical course can be very heterogeneous with some patients being safely observed over many years without ever requiring treatment to other patients having more rapidly progressive disease requiring multiple lines of treatment for disease control. Front-line treatment of advanced FL has historically consisted of chemoimmunotherapy but has extended to immunomodulatory agents such as lenalidomide. In the relapsed setting, several exciting therapies that target the underlying biology and immune microenvironment have emerged, most notable among them include targeted therapies such as phosphoinositide-3 kinase and Enhancer of Zeste 2 Polycomb Repressive Complex 2 inhibitors and cellular therapies including chimeric antigen receptor $T$ cells and bispecific T cell engagers. There are several combination therapies currently in clinical trials that appear promising. These therapies will likely reshape the treatment approach for patients with relapsed and refractory FL in the coming years. In this article, we provide a comprehensive review of the emerging and investigational therapies in $\mathrm{FL}$ and discuss how these agents will impact the therapeutic landscape in $\mathrm{FL}$.
\end{abstract}

Keywords: Follicular lymphoma, PI3Ki, EZH2, CART, BiTe

\section{Background}

Follicular lymphoma (FL) is the second most common subtype of non-Hodgkin lymphoma (NHL) accounting for around $20 \%$ of all cases of NHL $[1,2]$. FL most commonly presents either as a clinically enlarged lymph node(s) or incidentally on imaging performed for other reasons. The vast majority $(80 \%)$ of cases do not have B-type symptoms or cytopenias at the time of diagnosis [3]. Although not strictly pathognomonic, $85-90 \%$ have a $t(14: 18)$ chromosomal translocation juxtaposing B cell lymphoma 2 (BCL2) to the immunoglobulin heavy chain promoter resulting in the escape of the transformed

\footnotetext{
*Correspondence: Narendranath.Epperla@osumc.edu

${ }^{1}$ Division of Hematology, Department of Medicine, The James Cancer Hospital and Solove Research Institute, The Ohio State University, $460 \mathrm{~W}$ 10th Ave, Columbus, $\mathrm{OH}$ 43210, USA

Full list of author information is available at the end of the article
}

lymphocyte clone from the apoptotic death experienced by normal B-lymphocytes at the end of their lifespan. Interestingly, the $t(14: 18)$ can be found in nearly a quarter of healthy individuals regardless of age and gender with a similar distribution of breakpoints as in cases of FL $[4,5]$.

The extent of disease at diagnosis is the most important factor in the management of FL. Given the indolent nature of the disease, a majority of patients have advanced disease at diagnosis [6]. However, a subset of patients with well-localized disease limited to one to several lymph nodes can be successfully irradiated with long-term durable remissions. In this review, we provide a comprehensive overview of the emerging therapies and investigational approaches in relapsed/refractory (rel/ref) $\mathrm{FL}$ and briefly outline the advances in the frontline setting in advanced-stage disease requiring treatment. original author(s) and the source, provide a link to the Creative Commons licence, and indicate if changes were made. The images or other third party material in this article are included in the article's Creative Commons licence, unless indicated otherwise in a credit line to the material. If material is not included in the article's Creative Commons licence and your intended use is not permitted by statutory regulation or exceeds the permitted use, you will need to obtain permission directly from the copyright holder. To view a copy of this licence, visit http://creativecommons.org/licenses/by/4.0/. The Creative Commons Public Domain Dedication waiver (http://creativeco mmons.org/publicdomain/zero/1.0/) applies to the data made available in this article, unless otherwise stated in a credit line to the data. 


\section{Follicular lymphoma biology and disease pathogenesis}

It is now clear based on genomic studies that multiple other mutations are required in $\mathrm{FL}$, including genes involved in chromatin remodeling, nuclear factor-kappa light chain enhancer of activated B cells (NF- $\mathrm{B}$ ) signaling, Janus Kinase-Signal transducer and activator of transcription proteins (Jak-Stat) signaling, and B cell development [7]. The chromatin remodeling mutations not only involve histone-modifying genes such as cAMP response element-binding protein (CREBBP), E1A binding protein 300 (EP300), Enhancer of zeste homolog 2 (EZH2), and Myocyte enhancer factor 2B (MEF2B) but also the histones themselves, particularly histone $\mathrm{H} 1$, resulting in interruption of histone-DNA interface and chromatin compaction, thus underlining the central importance of chromatin remodeling disruption in the pathogenesis of FL. These studies also support the existence of a founding common progenitor clone (CPC) rich in chromatin remodeling mutations that remain persistent despite therapy giving rise to now only FL cells but transformed FL in the majority of cases.

The lymphoma microenvironment also plays an important role in the pathogenesis of FL and has been extensively reviewed elsewhere [8]. A large seminal study of the gene expression signatures from untreated FL patients $(n=191)$ identified that non-malignant immune infiltrating cells had a significant impact on the prognosis [9]. Although past studies have investigated the prognostic significance or time to transformation of several different immune cell subtypes, including tumor-associated macrophages, Treg cells, and follicular dendritic cells [10-13]. A recent comprehensive study using cytometry time of flight $(\mathrm{CyToF})$ on untreated FL samples $(n=31)$ showed a high degree of complexity of the infiltrating non-malignant $\mathrm{T}$ cells, distinguishing 12 distinct $\mathrm{CD} 4+\mathrm{T}$ cell subsets, some of which had prognostic significance including a population lacking the co-stimulatory markers CD27 and CD28[14]. It will be exciting to evaluate the significance of these immune subpopulations in light of many of the newer approved and emerging FL therapies discussed in this review, many of which rely on immune-based mechanisms for their cytotoxicity. However, at present, enumeration and transcriptional profiling of lymphoma-associated immune cells remain investigational without a clear role in FL therapeutic decision making.

\section{Relapsed/refractory follicular lymphoma-approved and investigational approaches}

Previously, the only therapy available after the failure of frontline chemoimmunotherapy was either chemoimmunotherapy regimens or immunomodulatory (IMid) therapy. However, over the past few years, there have been significant advancements with new therapies approved for patients with rel/ref disease as well as several others on the horizon (Fig. 1). In this section, we discuss the most current data surrounding the use of several small molecule inhibitors in relapsed FL, including lenalidomide, phosphoinositide 3 kinase (PI3K) inhibitors, epigenetic therapies, as well as other inhibitors not currently approved but under investigation either alone or in combination with other approved agents. We then discuss the role of antibodies/antibody-drug conjugates, checkpoint inhibitors, and cellular therapies in rel/ref FL.

\section{Immunomodulators}

Lenalidomide is a second-generation immunomodulatory agent that has a diverse range of anti-lymphoma activity which has been reviewed elsewhere [15]. It induces direct lymphoma cytotoxicity by promoting degradation of Ikaros zinc finger1 and Ikaros zinc finger3 (IKZF1 and IKZF3) by direct interaction and binding to the E3 ligase cereblon [16-18]. Degradation of cereblon also leads to an increase in p21 levels and a decrease in the levels of the transcription factor interferon regulatory factor 4 (IRF4) leading to inhibition of proliferation $[19,20]$. In addition, lenalidomide has significant immune-mediated anti-lymphoma activity by proliferation and activation of natural killer (NK) cells resulting in increased immune synapse formation and antibodydependent cell cytotoxicity [21]. Besides NK cells, lenalidomide leads to $\mathrm{T}$ cell stimulation and cytotoxicity and enhanced dendritic cell presentation $[22,23]$.

The activity of lenalidomide in rel/ref FL was initially studied in the CALGB 50,401 study, which was a randomized phase II three-arm study in which lenalidomide, rituximab, or lenalidomide plus rituximab (R2) were compared [24]. The rituximab-only arm was eventually dropped due to poor accrual. R2 was found to have a longer median progression-free survival (PFS) compared to lenalidomide alone ( 2 years vs 1.1 years). More patients in the R2 arm completed the full 12 months of treatment (63\% vs $36 \%$ ) due to more progression seen in the lenalidomide group. The R2 regimen was further studied in the phase III AUGMENT study which enrolled patients with FL or marginal zone lymphoma (MZL) who had previous chemotherapy or immunotherapy with at least 2 or more doses of prior rituximab. Patients with rituximab refractoriness were excluded in this trial [25]. Rituximab alone or R2 were compared with lenalidomide administered at $20 \mathrm{mg}$ daily on days $1-21$ of a 28 -day cycle for 12 months while rituximab was given for the first 6 cycles. The median PFS was superior for patients receiving R2 compared to rituximab alone (39.4 months versus 14.1 months) but with a higher incidence of infections 


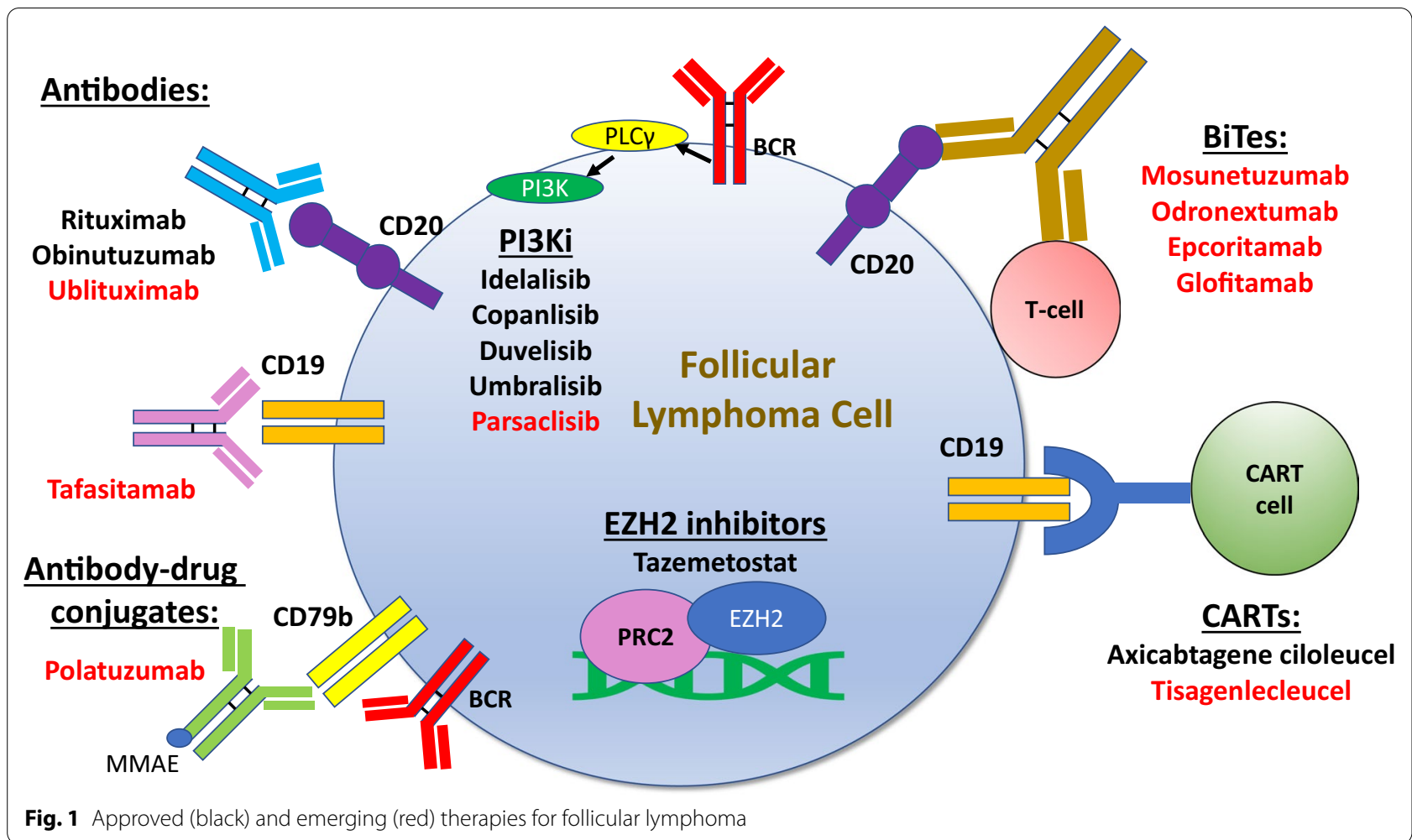

(63\% v 49\%), neutropenia (58\% v 23\%), and rash (32\% v $12 \%)$. These data lead to subsequent FDA approval of R2 for rel/ref FL in May of 2019. The phase IIIb MAGNIFY trial is investigating if a longer duration of lenalidomide past one year would further improve patient outcomes. Patients in this trial are randomized to either rituximab maintenance or continued $\mathrm{R} 2$ after received one year of R2. An interim analysis at ASCO 2019 showed a tolerable safety profile with $38 \%$ of target enrollment randomized to maintenance accrued [26].

Lenalidomide has also be studied with obinutuzumab (LG), a glycoengineered anti-CD20 antibody with higher antibody-dependent cell cytotoxicity at the expense of diminished complement-dependent cytotoxicity [27]. This combination was demonstrated to be safe with lenalidomide dosing of $20 \mathrm{mg}$ (12 cycles) and obinutuzumab dosage of $1000 \mathrm{mg} / \mathrm{m} 2$ (6 cycles) in a phase $1 / 2$ study of relapsed indolent lymphomas [28]. In the GALEN study $(n=86)$, the overall response rate (ORR) and complete response (CR) rates were $79 \%$ and $38 \%$, respectively [29]. It is important to note that $23 \%$ of patients included in the study were refractory to rituximab and $27 \%$ had progression within 24 months of initial treatment (POD24). The PFS at 2 years was $65 \%$, with $34 \%$ of patients experiencing a serious adverse event (SAE) including basal cell carcinoma (6\%), febrile neutropenia (5\%), and infusion-related reactions (4\%). As there have not been any randomized studies directly comparing LG versus R2 in $\mathrm{rel} / \mathrm{ref} \mathrm{FL}$, the advantage of LG over R2 in this setting, particularly in patients without rituximab refractoriness, is currently unclear.

\section{Small molecule inhibitors}

\section{PI3K inhibitors}

The phosphoinositide 3 kinases (PI3Ks) are a family of intracellular signal transduction kinases that phosphorylate the 3' position of the inositol ring of phosphatidylinositol present in the lipid membrane [30]. This gives rise to phosphatidylinositol 3,4,5 triphosphate (PIP3) which binds to the pleckstrin homology domain located in a variety of kinases including Protein Kinase B (PKB or Akt) and phosphoinositide-dependent kinase1 (PDK1 leading to increases in cell metabolism, growth and cell division. The PI3Ks are divided into three classes (class I, II, III) based on their structure, regulation, and lipid substrates [31]. The class I kinases include PI3K $\alpha, \beta, \gamma$, and $\delta$. PI3K $\alpha$ and PI3K $\beta$ are expressed in all cells while PI3K $\delta$ and PI3K $\gamma$ and expressed primarily in leukocytes. In B cells, $\mathrm{PI} 3 \mathrm{~K} \delta$ plays an important and nonredundant role in $B$ cell receptor (BCR) signaling and B cell activation [32-34]. PI3K $\gamma$ has been shown to play an important role in innate immune migration to the tumor microenvironment and inhibition of $\mathrm{PI} 3 \mathrm{~K} \gamma$ was sufficient to prevent 
this action [35]. The best strategy of PI3K isoform inhibition for the greatest therapeutic efficacy in lymphomas remains an open question. Four PI3K inhibitors are currently approved for FL (idelalisib, copanlisib, duvelisib, umbralisib) with many others are under active investigation (Table 1).

\section{Approved PI3Ki}

Idelalisib, a PI3K $\delta$ selective inhibitor, was the first approved PI3K inhibitor (PI3Ki) for relapsed FL based on a phase II study $(n=125)$ of heavily pretreated patients (median prior lines of therapy $=4$ ) with indolent NHL ( $58 \%$ of which were $\mathrm{FL}$ ), showing a median PFS of 11 months [36]. Potentially life-threatening autoimmune grade 3-4 AEs including colitis, hepatitis, and pneumonitis can occur at any time during treatment [37] and must be immediately recognized as the patients may require a short course of systemic steroids after exclusion of infectious causes [38]. In addition, opportunistic infections including pneumocystis jiroveci pneumonia (PJP) and cytomegalovirus (CMV) reactivation can occur with regular monitoring for CMV indicated while on therapy. Copanlisib is a PI3K $\alpha / \delta$ inhibitor which shown a median PFS of 12.5 months ( $n=142$ pts, $73 \%$ with FL) in the phase II CHRONOS-1 study leading to its approval [39, 40]. Its overall safety profile is more favorable than idelalisib, although hyperglycemia and hypertension were seen at a higher rate with copanlisib which can be explained in part, at least for the hyperglycemia, by greater PI3K $\alpha$ inhibition.

Duvelisib is a PI3K $\delta / \gamma$ inhibitor currently approved for FL treatment based on the DYNAMO trial which showed a PFS of 9.5 months ( $n=129$ pts, $64 \%$ with FL), with diarrhea $(48.8 \%)$, nausea (29.5\%), and neutropenia (28.7\%) being the most common side effects [41]. It is important to note that a greater proportion of patients included in the study were refractory to prior chemo-immunotherapy (77\%).

Umbralisib is a PI3K $\delta$ selective inhibitor that also has activity against casein kinase (CK)1-epsilon proteins. The CK1 proteins are a family of proteins that are involved in various processes including DNA repair, mitotic checkpoint signaling, and the immune response [42]. In particular, CK1ع plays an important role in the translation of lymphoma oncogenes as well as the Wnt- $\beta$ catenin pathway. Of note, in a mouse model of CLL, treatment with umbralisib led to less intestinal and liver inflammation compared with idelalisib and duvelisib and correlated with a higher number of peripheral Treg cells in umbralisib mice, suggesting there may be a protective effect of CK1 1 inhibition from the autoimmune toxicities induced by PI3K inhibition [43]. In a study of rel/ref indolent lymphomas including FL, single-agent umbralisib $(n=117)$ showed an ORR and CR rate of $45.3 \%$ and a $5.1 \%$, respectively with a median PFS of 10.6 months[44] leading to its accelerated approval for rel/ref FL after at least three prior lines of therapy in February of 2021.

\section{Emerging PI3Ki}

Given the ongoing serious risk of autoimmune toxicity and infectious complications with long-term PI3K inhibition, particularly with strong PI3K $\delta$ blockade, there is significant interest in balancing the anti-tumor effects with these toxicities. A possible way of mitigating these risks is with intermittent or induction/maintenance dosing schemes instead of continuous dosing. However, there are no ongoing trials with approved PI3K inhibitors comparing alternate dosing schemes and current approaches have rather focused on developing new PI3K inhibitors with better efficacy and/or safety profiles.

Parsaclisib is a structurally distinct PI $3 K \delta$ selective inhibitor with an overall greater potent inhibition of PI3K $\delta$ than the other currently approved PI3K inhibitors. Early results from a phase $1 / 2$ of parsaclisib with and without itacitinib, a selective JAK1 inhibitor, showed an ORR and CR rate of $63 \%$ and $13 \%$ in the monotherapy arm in FL patients $(n=5)$ with results awaited from an ongoing phase 2 study in rel/ref FL (NCT03126019) [45]. Other PI3K $\delta$ inhibitors currently in phase 2 clinical trials include zandelisib (ME-401, a selective PI3K $\delta$ inhibitor, NCT03768505) and YY-20394 (a selective PI3K $\delta$ inhibitor, NCT04370405) and tenalisib (PI3K $\delta / \gamma$ inhibitor, NCT03711578). Many drugs with dual PI3K/mammalian target of rapamycin (mTOR) inhibition have also been developed but their utility in providing improved efficacy at the expense of toxicity given their safety profiles in clinical trials is unclear [46].

\section{Combinatorial approaches incorporating PI3Ki}

Combinatorial approaches with approved PI3K inhibitors are currently ongoing and have been nicely detailed in a recent review [47]. In the cooperative group trial, when idelalisib was combined with R2, there was significant hepatic toxicity with 2 of 7 enrolled patients passing away from toxicity, one from hepatic failure and another from complications related to colitis leading to premature closure of the study [48]. Given the overall better safety profile of copanlisib, duvelisib and umbralisib compared to idelalisib, these PI3Kis may be better suited to be incorporated into combination treatment strategies either with chemotherapy or immunomodulatory agents. The preliminary results of a phase III study incorporating copanlisib into chemoimmunotherapy with either R-CHOP or $B R$ in the relapsed setting showed an ORR and CR rate of $90 \%$ and $50 \%$, respectively for BR + copanlisib $(n=10)$ and $100 \%$ and $30 \%$, respectively for R-CHOP + copanlisib 
Table 1 PI3K inhibitors in FL (includes completed and ongoing trials)

\begin{tabular}{|c|c|c|c|c|c|c|c|c|c|}
\hline Treatment & $\begin{array}{l}\text { Target } \\
\text { specificity }\end{array}$ & $\begin{array}{l}\text { Publication/ } \\
\text { NCT\# }\end{array}$ & Phase & Total $n[\mathrm{FL}]$ & $\begin{array}{l}\text { Median } \\
\text { lines of prior } \\
\text { therapy }\end{array}$ & ORR\% ${ }^{\mathrm{a}}[\mathrm{CR} \%]$ & $\begin{array}{l}\text { Median PFS } \\
\text { (mos) }\end{array}$ & $\begin{array}{l}\text { Grade } \geq 3 \text { AEs } \\
(\%)^{b}\end{array}$ & Approved \\
\hline \multicolumn{10}{|l|}{ Single agent studies } \\
\hline Idelalisib & $\delta$ & {$[36]$} & $\|$ & $125[72]$ & 4 & $45[3]$ & 11 & $\begin{array}{l}\text { Neutropenia } \\
\text { [27], LFT } \\
\text { elevation } \\
\text { [13], diarrhea } \\
\text { [13], PNA [7] }\end{array}$ & + \\
\hline Copanlisib & $a / \delta$ & {$[39,40]$} & $\|$ & $142[104]$ & 3 & $59[20]$ & 12.5 & $\begin{array}{l}\text { Hyperglycemia } \\
\text { [40], Hyper- } \\
\text { tension [24], } \\
\text { Neutropenia } \\
\text { [24] }\end{array}$ & + \\
\hline Duvelisib & $\delta / \gamma$ & [41] & $\|$ & $129[83]$ & 3 & $42[1]$ & 9.5 & $\begin{array}{l}\text { Neutropenia } \\
\text { [25], anemia } \\
\text { [15], diar- } \\
\text { rhea [15], } \\
\text { thrombocy- } \\
\text { topenia [12], } \\
\text { LFT rise [5], } \\
\text { lipase rise } \\
\text { [7], colitis [5], } \\
\text { PNA [5], }\end{array}$ & + \\
\hline Umbralisib & $\delta, C K 1 \varepsilon$ & [44] & $\|$ & 208 [117] & 2 & $45[5]$ & 10.6 & $\begin{array}{l}\text { Neutropenia } \\
\text { [11], diarrhea } \\
\text { [10], LFT } \\
\text { rise [7] }\end{array}$ & + \\
\hline Parsaclisib & $\delta$ & NCT03126019 & $\|$ & $N A^{c}$ & $N A^{c}$ & $N A^{c}$ & $N A^{c}$ & $N A^{c}$ & - \\
\hline Zandelisib & $\delta$ & NCT03768505 & $\|$ & $N A^{c}$ & $N A^{c}$ & $N A^{c}$ & $N A^{c}$ & $N A^{c}$ & - \\
\hline YY-20394 & $\delta$ & NCT04370405 & $\|$ & $N A^{c}$ & $N A^{c}$ & $N A^{c}$ & $N A^{c}$ & $N A^{c}$ & - \\
\hline Tenalisib & $\delta / \gamma$ & NCT03711578 & $\|$ & $N A^{c}$ & $N A^{c}$ & $N A^{c}$ & $N A^{c}$ & $N A^{c}$ & - \\
\hline \multicolumn{10}{|l|}{ Combination studies } \\
\hline Duvelisib + BR or R & $\delta / \gamma$ & {$[50]$} & । & $46[15]$ & 2 & $\begin{array}{l}\text { Duvelisib + R: } \\
62 \text { [19], Duv- } \\
\text { elisib + BR: } \\
58[17]^{d}\end{array}$ & $\begin{array}{l}\text { Duvelisib + R: } \\
\text { 10.7, Duv- } \\
\text { elisib + BR: } \\
5.3^{\mathrm{d}}\end{array}$ & $\begin{array}{l}\text { Neutropenia } \\
\text { [41], rash } \\
\text { [20], diarrhea } \\
\text { [13] }\end{array}$ & - \\
\hline $\begin{array}{l}\text { Umbral- } \\
\text { isib + ublituximab }\end{array}$ & $\delta, C K 1 \varepsilon$ & [51] & I & 75 [19] & 3 & $44[22]$ & NP & $\begin{array}{l}\text { Neutropenia } \\
\text { [28], PNA [8], } \\
\text { diarrhea [8], } \\
\text { abdominal } \\
\text { pain [7], } \\
\text { thrombocy- } \\
\text { topenia [5] }\end{array}$ & - \\
\hline $\begin{array}{l}\text { Copanlisib + BR or } \\
\text { R-CHOP }\end{array}$ & $a / \delta$ & NCT03711578 & III & $N A^{c}$ & $N A^{c}$ & $N A^{c}$ & $N A^{c}$ & $N A^{c}$ & - \\
\hline $\begin{array}{l}\text { Duvel- } \\
\text { isib + nivolumab }\end{array}$ & $\delta / \gamma$ & NCT03892044 & । & $N A^{c}$ & $N A^{c}$ & $N A^{c}$ & $N A^{c}$ & $N A^{c}$ & - \\
\hline $\begin{array}{l}\text { Idelalisib + pem- } \\
\text { brolizumab }\end{array}$ & $\delta$ & NCT02332980 & $\|$ & $N A^{c}$ & $N A^{c}$ & $N A^{c}$ & $N A^{c}$ & $N A^{c}$ & - \\
\hline $\begin{array}{l}\text { Duvelisib + acala- } \\
\text { brutinib }\end{array}$ & $\delta / \gamma$ & NCT04836832 & $|/| \mid$ & $N A^{c}$ & $N A^{c}$ & $N A^{c}$ & $N A^{c}$ & $N A^{c}$ & - \\
\hline $\begin{array}{l}\text { Umbralisib + pem- } \\
\text { brolizumab }\end{array}$ & $\delta, C K 1 \varepsilon$ & NCT03283137 & । & $N A^{c}$ & $N A^{c}$ & $N A^{c}$ & $N A^{c}$ & $N A^{c}$ & - \\
\hline $\begin{array}{l}\text { Umbral- } \\
\text { isib + ublituxi- } \\
\text { mab + lenalido- } \\
\text { mide }\end{array}$ & $\delta, C K 1 \varepsilon$ & NCT04635683 & । & $N A^{c}$ & $N A^{c}$ & $N A^{c}$ & $N A^{c}$ & $N A^{c}$ & - \\
\hline
\end{tabular}

Abbreviations: AEs—adverse events; $\mathrm{BR}$ —-bendamustine and rituximab; $\mathrm{CR}$ —complete response rate; NP—not presented; ORR—overall response rate; PFS— progression-free survival; PNA— pneumonia; R-CHOP—rituximab, cyclophosphamide, doxorubicin, vincristine, and prednisone

${ }^{a}$ Response rates for $\mathrm{FL}$ subset 
Table 1 (continued)

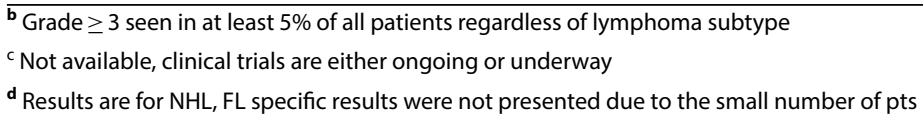

[49]. Four patients within the BR + copanlisib group and five patients within the $\mathrm{R}-\mathrm{CHOP}+$ copanlisib group required discontinuation of treatment due to AEs. Pneumonitis did occur in one patient but no AEs related to colitis or hepatic failure were reported. Likewise, duvelisib was also studied in combination with BR in patients with relapsed chronic lymphocytic leukemia (CLL) or NHL ( $n=29$ including both indolent and aggressive lymphomas, 15 of which had FL) in phase I study with a doseexpansion phase [50]. Thirty-seven percent of patients experienced an SAE with $19.6 \%$ of patients determined to be related to duvelisib, including cases of CMV colitis, CMV esophagitis, inflammatory colitis, acute lung injury, and generalized rash, with no cases of hepatitis. The limited numbers of FL patients in this study preclude efficacy analysis, but given the serious toxicities when combining duvelisib with bendamustine likely related to the significant lymphosuppression, the role of combination duvelisib + bendamustine versus reserving duvelisib monotherapy for a later line is unclear. In the FRESCO trial (NCT02605694) duvelisib was combined with either rituximab or $\mathrm{R}-\mathrm{CHOP}$ for patients with progression within the first 24 months after initial therapy but was subsequently withdrawn by the sponsor.

Combination studies with umbralisib are currently under investigation. The combination of obinutuzumab and umbralisib is one of the three arms of the ongoing SWOG1608 phase II trial (see Approach to the POD24 patient). An initial phase I study combining umbralisib with the novel anti-CD20 antibody ublituximab (U2) in $\mathrm{rel} /$ ref B-NHL and CLL found this combination to be safe with no new safety signals compared to the umbralisib alone with an ORR and CR rate of $46 \%$ and $17 \%$, respectively[51]. As discussed earlier, given the overall reduced potential for autoimmune toxicity of umbralisib compared to the other PI3K inhibitors, combination therapies of umbralisib with lenalidomide/ anti-CD20 combinations may be safer with strong anti-FL activity. A clinical trial combining U2 along with lenalidomide (NCT04635683) is currently ongoing.

Another potential area of interest is combining PI3Ki with Bruton's tyrosine kinase (BTK) inhibitors given the synergy and potentially non-overlapping toxicity. Acalabrutinib was studied in combination with PI $3 K \delta$ inhibitor and was shown to be safe and tolerable in early phase clinical trials in rel/ref B cell malignancies [52]. A phase $\mathrm{Ib} / \mathrm{II}$ study is underway looking at the combination of acalabrutinib and duvelisib in rel/ref indolent NHLs (NCT04836832).

\section{Epigenetic therapies}

Epigenetic regulation of lymphoid malignancies is currently an exciting area of research with significant potential for new therapies [53]. Given the shifts in methylated genes during transit through the germinal center (GC) during normal B cell differentiation, it is not surprising that epigenetic regulators have surfaced as undergoing mutation and dysregulation in germinal center (GC) derived B cell malignancies, such as FL [54]. Nearly $90 \%$ of FL have mutations in the histone methyltransferase, lysine methyltransferase 2A (KMT2A), and 60\% in the acetyltransferase CREBBP. Around $80 \%$ of FL have cooccurring epigenetic mutations with most mutations being the loss of function mutations $[55,56]$. In this section, we will review different classes of epigenetic modifiers that can serve as potential therapies in FL (Table 2).

\section{$E Z H 2$ inhibitors}

$\mathrm{EZH} 2$ is histone lysine methyltransferase gene, which as a part of the polycomb repressor complex 2 (PRC2), catalyzes the addition of methyl groups to $\mathrm{K} 27$ of $\mathrm{H} 3$. This leads to transcriptional repression of target genes. $\mathrm{EZH} 2$ is important in the formation of $\mathrm{GC}$ in mice and it has been shown that mutations in $\mathrm{EZH} 2$ in addition to overexpression of BCL2 lead to B cell lymphomas [57]. EZH2 may also have immune modulatory effects wherein it suppresses the immune effector trafficking by repressing Th1 type cytokines [58]. EZH2 is mutated in 20\% of FL with the vast majority of mutations resulting in the substitution of tyrosine 641 leading to gain of function of methyltransferase activity. This distinguishes EZH2 mutations from most other epigenetic enzyme mutations which are loss of function mutations and thus provide a more readily available therapeutic target. Tazemetostat is a first-in-class oral inhibitor of EZH2 that has shown an overall favorable safety profile in the first in human phase I study of patients with rel/ref NHL [59]. The phase 2 study of tazemetostat in relapsed FL (who received 2 or more prior therapies, $n=99$ ) demonstrated an ORR of $69 \%$ and $35 \%$ in EZH2 mutant $(n=45)$ and wild type $(n=54)$ patients, respectively, with a median PFS of 13.8 months and 11.1 months [60]. Grade 3 treatment-related AEs were infrequent and included thrombocytopenia (3\%), neutropenia (3\%), and anemia (2\%). 
Table 2 Epigenetic therapies in past and ongoing trials open to FL patients

\begin{tabular}{|c|c|c|c|c|c|c|c|c|c|}
\hline Treatment & Target & $\begin{array}{l}\text { Publication/ } \\
\text { NCT\# }\end{array}$ & Phase & Total $n$ [FL] & $\begin{array}{l}\text { Median } \\
\text { lines of prior } \\
\text { therapy }\end{array}$ & ORR\% ${ }^{\mathrm{a}}[\mathrm{CR} \%]$ & $\begin{array}{l}\text { Median PFS } \\
\text { (mos) }\end{array}$ & $\begin{array}{l}\text { Grade } \geq 3 \\
\text { AEs }(\%)^{b}\end{array}$ & Approved \\
\hline \multicolumn{10}{|l|}{ EZH2 inhibitors } \\
\hline Tazemetostat & $\mathrm{EZH} 2$ & {$[60]$} & $\|$ & $\begin{array}{l}99[99 ; \text { MT 45, } \\
\text { WT 45) }\end{array}$ & 2 & $\begin{array}{l}\text { MT: } 69 \text { [13] } \\
\text { WT: } 35 \text { [4] }\end{array}$ & $\begin{array}{l}\text { MT: } 13.8 \mathrm{WT}: \\
11.1\end{array}$ & None $^{c}$ & + \\
\hline $\begin{array}{l}\text { Tazemeto- } \\
\text { stat + rituximab }\end{array}$ & $\mathrm{EZH} 2$ & NCT04762160 & $\|$ & $N A^{d}$ & $N A^{d}$ & $N A^{d}$ & $N A^{d}$ & $N A^{d}$ & - \\
\hline $\begin{array}{l}\text { Tazemeto- } \\
\text { stat + lenalido- } \\
\text { mide + rituxi- } \\
\text { mab }\end{array}$ & $\mathrm{EZH} 2$ & NCT04224493 & 1 & $N A^{d}$ & $N A^{d}$ & $N A^{d}$ & $N A^{d}$ & $N A^{d}$ & - \\
\hline \multicolumn{10}{|l|}{ HDAC inhibitors } \\
\hline Vorinostat & $\begin{array}{l}\text { Class } 1 \text { and } 2 \\
\text { HDACs }\end{array}$ & {$[62]$} & $\|$ & 50 [39] & 1 & $49[10]$ & 20 & $\begin{array}{l}\text { Neutrope- } \\
\text { nia [36], } \\
\text { thrombocy- } \\
\text { topenia [23], } \\
\text { lympho- } \\
\text { penia [13], } \\
\text { diarrhea [5], } \\
\text { anorexia [7] }\end{array}$ & - \\
\hline $\begin{array}{l}\text { Vorinostat + rituxi- } \\
\text { mab }\end{array}$ & $\begin{array}{l}\text { Class } 1 \text { and } 2 \\
\text { HDACs }\end{array}$ & {$[64]$} & $\|$ & 28 [22] & 2 & $41[27]$ & 18.8 & $\begin{array}{l}\text { Lymphopenia } \\
\text { [25], throm- } \\
\text { bocytopenia } \\
\text { [18], neutro- } \\
\text { penia [11], } \\
\text { fatigue [32], } \\
\text { thrombosis } \\
\text { [14], dehy- } \\
\text { dration [11], } \\
\text { hypergly- } \\
\text { cemia [11] } \\
\text { hypotension } \\
\text { [7], PNA [7], }\end{array}$ & - \\
\hline Mocetinostat & $\operatorname{HDAC} 1,2,3,11$ & {$[66]$} & $\|$ & $72[31]$ & 4 & $11[4]$ & 26.3 & $\begin{array}{l}\text { Fatigue [24], } \\
\text { neutropenia } \\
\text { [15], throm- } \\
\text { bocytopenia } \\
\text { [12], anemia } \\
\text { [8] }\end{array}$ & - \\
\hline \multicolumn{10}{|l|}{ DNMT inhibitors } \\
\hline $\begin{array}{l}\text { 5-azacyti- } \\
\text { dine + R-CHOP }\end{array}$ & DNMT1 & {$[68]$} & 1 & $10[3]$ & 3 & 66 [33] & NP & $\begin{array}{l}\text { Neutropenia } \\
\text { [50], throm- } \\
\text { bocytopenia } \\
\text { [40], anemia } \\
\text { [20], abscess } \\
\text { [10], ano- } \\
\text { rexia [10], } \\
\text { bacteremia } \\
\text { [10], nausea } \\
\text { [10] }\end{array}$ & - \\
\hline \multicolumn{10}{|l|}{ PRMT inhibitors } \\
\hline GSK3326595 & PRMT5 & NCT02783300e & 1 & $N A^{d}$ & $N A^{d}$ & $N A^{d}$ & $N A^{d}$ & $N A^{d}$ & - \\
\hline JNJ-64619178 & PRMT5 & NCT03573310 & 1 & $N A^{d}$ & $N A^{d}$ & $N A^{d}$ & $N A^{d}$ & $N A^{d}$ & - \\
\hline \multicolumn{10}{|l|}{ BET inhibitors } \\
\hline CPI-0610 & BRD2, BRD4 & {$[74]$} & I & $44[8]$ & 4 & $12[0]$ & NP & NP & - \\
\hline
\end{tabular}

Abbreviations: AEs—adverse events; $\mathrm{CR}$ —complete response rate; $\mathrm{MT}$ —-mutant $\mathrm{EZH} 2$; $\mathrm{NP}$ —not presented; ORR—overall response rate; $\mathrm{PFS}$ - progression-free survival; PNA—pneumonia; R-CHOP_rituximab, cyclophosphamide, doxorubicin, vincristine and prednisone; WT—wild type EZH2

${ }^{a}$ Response rates in FL subset

${ }^{b}$ Grade $\geq 3$ seen in at least $5 \%$ of all patients regardless of lymphoma subtype

' No grade $\geq 3$ events occurred in greater than $5 \%$ of patients, thrombocytopenia [3], neutropenia [3], anemia [2] 
Table 2 (continued)

${ }^{\mathrm{d}}$ Not available, clinical trials are ongoing

e first in human study enrolling patients with NHL or solid tumors

Tazemetostat is an attractive therapeutic option, especially in elderly patients or patients with co-morbidities that may preclude other therapies such as PI3Ki or chemotherapy given the clinical activity and favorable safety profile.

Valemetostat is a dual EZH1/2 inhibitor that has shown activity in both $\mathrm{B}$ and $\mathrm{T}$ cell NHLs in the Japanese population with an ORR of $53 \%$ with a particularly high response rate in $\mathrm{T}$ cell NHLs $(\mathrm{ORR}=80 \%)$ [61]. The study is currently enrolling patients with $\mathrm{T}$ cell NHLs within the dose-expansion phase. Whether dual inhibition of EZH1/2 offers any benefit compared to selective EZH2 inhibition in FL is an open question that warrants further investigation.

\section{Histone deacetylase inhibitors (HDACi)}

Vorinostat is an oral inhibitor of class I and 2 HDACs and is currently approved for the treatment of T cell NHLs. As discussed previously, given the high rate of acetyltransferase loss of function mutations in FL, another potential therapeutic approach to counteract the loss of histone acetylation marks in these FLs would be to target the histone deacetylases to try to restore epigenetic homeostasis in these tumors. In a phase II study of relapsed indolent lymphomas and mantle cell lymphoma (MCL) ( $n=56,39$ with FL), the ORR was $49 \%$ in the subset of patients with FL with a median PFS of 20 months. The toxicity was limited to cytopenias which were easily managed [62]. Mutation analysis revealed a mutation rate of $67.7 \%$ and $21.4 \%$ in CREBBP and EP300, respectively, with no correlation between the presence of a mutation and clinical response to vorinostat, although the limited number of patients precludes the determination of these mutations as predictive markers of response. Preclinical work has shown that inhibition of HDAC6 can lead to upregulation of CD20 with enhanced efficacy with anti-CD20 antibodies [63]. In a phase II study of rituximab in combination with vorinostat in newly diagnosed and rel/ref indolent B-NHLs (22 of 28 were FL), the ORR and median PFS were $41 \%$ and 18.8 months, respectively in the previously treated patients [64]. Patients who achieved a CR $(n=10)$ were allowed to come off treatment after 2 additional cycles of therapy with the option of retreatment upon relapse. Six remained in CR after a median follow-up of 27 months and of the 4 patients who underwent retreatment, 2 achieved a second CR, suggesting that time-limited therapy may be possible with this combination. It is unclear if vorinostat could resensitize rituximab refractory patients given the lack of information on rituximab refractoriness in the study. Studies of combination chemoimmunotherapy with vorinostat have largely been limited to diffuse large B cell lymphoma (DLBCL) with a few FL patients enrolled in these studies. The pan-HDAC inhibitor panobinostat that is currently approved for relapsed multiple myeloma has been studied in B-NHLs in early phase clinical trials in combination with mTOR inhibitor everolimus which inhibits cell proliferation by inhibiting protein translation [65]. Thrombocytopenia was the primary dose-limiting toxicity (DLT) with a median PFS of 4 months in FL patients. Studies on newer HDAC inhibitors, including abexinostat, mocetinostat, belinostat, entinostat, quisinostat, and chidamide have largely focused on T cell NHLs and aggressive lymphomas, except for mocetinostat which showed modest single-agent activity in FL. In a phase II trial of rel/ref DLBCL and FL, the ORR was $11.5 \%$ in the FL cohort $(n=31)[66]$.

\section{Inhibitors of DNA methyltransferases (DNMT inhibitors)}

The DNMTs have an opposing role to chromatin acetyltransferases by the methylation of DNA leading to transcriptional repression by maintaining or inducing a closed chromatin state thus precluding the binding of transcription factors. The DNMT inhibitors, 5-azacytidine, and decitabine have been established as effective therapeutics in myelodysplastic syndrome (MDS) and Acute Myeloid Leukemia (AML). In a small phase I study of low dose decitabine in patients with rel/ref CLL and DLBCL $(n=20)$, no responses were seen with 8 patients having a stable disease with correlative studies showing no differences in DNA methylation [67]. In another preliminary analysis of a study incorporating 5-azacytidine with R-CHOP in rel/ref lymphomas $(n=10,3$ with FL), one CR and one PR awere seen in the FL patients [68]. Given that only small DNMT inhibitor trials with limited numbers of FL patients have been reported, the potential of DNMT inhibitors in FL is currently unclear.

\section{Inhibitors of Protein arginine methyltransferases (PRMT inhibitors)}

The PRMTs catalyze the mono or dimethylation of histones, with PRMT5 being overexpressed in NHLs [69]. In addition, PRMT5, like EZH2, is required for GC formation and lymphoma survival through its interaction with BCL6, and thus, like EZH2, may also be important in the maintenance of epigenetic dysregulation in FL [70]. 
PRMT5 inhibitors have shown significant activity in preclinical models of Epstein Barr virus $(\mathrm{EBV}+)$ lymphomas, DLBCL, and MCL [71, 72]. Clinical trials of PRMT5 inhibitors including GSK3326595 (NCT02783300) and PF-06939999 (NCT03854227) are currently in the early stages of development. PRMT5 inhibition holds promise as another epigenetic therapy for FL.

\section{Inhibitors of Bromodomain and Extraterminal Motif (BET) proteins}

The BET proteins are a group of "histone readers" that act downstream of histone acetylation by binding to histone acetyl marks and recruiting transcription factors to DNA. Birabresib was the first BET to be evaluated in a clinical trial, but with no responses seen in DLBCL patients $(n=2)$ in the first-in-human study [73]. In another preliminary analysis of a dose escalation phase I study of the BET inhibitor CPI-0610 in B-NHL ( $n=44,8$ with FL), one PR was seen in FL patients [74]. Thus far, response rates have been very modest and the high rate of histone acetyltransferase mutations in FL likely may result in resistance to this class of inhibitors. Restoration of acetyl marks by other epigenetic therapies may be required for the improvement of responses to these inhibitors.

\section{Combinatorial approaches using epigenetic therapies}

At present, the therapeutic potential of many epigenetic therapies may likely lie in novel combinations of already approved agents or rational combinations defined by synergy in the pre-clinical studies. A phase II trial of tazemetostat with rituximab (NCT04762160) and a phase I trial incorporating R2 with tazemetostat (NCT04224493) both in rel/ref FL after one prior line of therapy are currently underway. The interaction of other epigenetic modifiers with EZH2 is an exciting avenue of research. Preclinical work using a combination of acetyltransferase and methyltransferase inhibitors with EZH2 inhibition and profiling of epigenetic and downstream transcriptional changes will likely uncover interesting and novel combinations of epigenetic therapies with more potent clinical activity and will hopefully lead the way to rational clinical studies of epigenetic therapies in FL.

\section{$B C L 2$ inhibitors}

There was initially significant optimism in targeting the BCL2 in FL given the nearly universal presence of the 14:18 translocation in FL leading to overexpression of BCL2 resulting in escape from apoptosis. In contrast to other hematologic malignancies like CLL, MCL, AML, and MDS where venetoclax shows significant clinical activity, the response rate in FL has been modest with an ORR of $38 \%$ and a median PFS of 11 months [75]. This suggests the need to explore combination strategies with BCL2 inhibitors in the FL patient population.

The phase 2 CONTRALTO study was a three-arm study investigating the efficacy of venetoclax in combination with rituximab (chemo-free-arm, VR, Arm A), venetoclax with bendamustine and rituximab (VBR, Arm B), and standard of care bendamustine + rituximab (BR, Arm C) [76]. Venetoclax was given for a total of 12 cycles in both investigational arms with a safety run-in in the venetoclax + BR arm. Frequent dose reductions or delays were seen in Arm B due to neutropenia and diarrhea resulting in a reduction in the dose of BR. The ORR and $\mathrm{CR}$ rates were higher in the chemotherapy arms (Arm A 35\% and 17\%; Arm B 84\% and 75\%; Arm C 84\% and 69\%) with similar duration of response and PFS between Arm $\mathrm{B}$ and $\mathrm{C}$. Due to the overlapping hematologic toxicities of venetoclax and chemotherapy, it is likely that a more optimized dosing schedule will need to be defined before combined chemotherapy and venetoclax will be useful in clinical practice.

The utility of BCL2 inhibition may be realized by combination with other targeted agents which may not only obviate the limited dosing due to hematologic toxicity but also increase efficacy based on more rationale mechanisms of cytotoxicity. Along these lines, the combination of ibrutinib and venetoclax is a therapy that is being explored across CLL, MCL as well as FL. Results of a phase I trial in rel/ref FL were recently presented at ASH 2020 and showed an ORR and CR rate $(n=16)$ of $69 \%$ and $25 \%$ with a safety profile similar to other studies of this combination with the most common grade $\geq 3$ AEs including neutropenia (25\%), thrombocytopenia (13\%), lung infection (13\%), and atrial fibrillation (6\%) [77]. A phase II study of ibrutinib + venetoclax is currently ongoing (NCT02956382).

\section{BCR pathway inhibitors}

Given the significant success of Btk inhibition in CLL and MCL, the efficacy of Btk inhibition in rel/ref FL was explored in a phase 2 trial of ibrutinib monotherapy (DAWN trial) [78]. Ibrutinib was given at a dosage of $560 \mathrm{mg}$ until disease progression or unacceptable toxicity. At a median follow-up of 27.7 months $(n=110)$, the ORR and CR rates were $20.9 \%$ and $11 \%$ with a median PFS of 4.6 months and thus did not meet its primary efficacy endpoint. Another phase 2 trial showed an ORR and CR rate of $37.5 \%$ and $12.5 \%$ with a median PFS of 14 months [79]. The authors did note an increased response rate in rituximab sensitive disease $(52.6 \%$ vs $16.7 \%)$ as well as resistance in patients with caspase recruitment domain family member11 (CARD11) mutations, suggesting pre-selection of patients based on these variables may allow better efficacy of Btki in rel/ref FL. As is the case 
with BCL2 inhibition, the role of Btk inhibition in FL is unclear at the present time and its potential will likely need to be defined with the use of rational combination treatments.

\section{Antibodies and antibody-drug conjugates (ADCs)}

Ever since the introduction of rituximab that revolutionized the treatment of B cell NHL, new antibody therapies, including ofatumumab, obinutuzumab, and most recently tafasitamab and ADCs including brentuximab, and polatuzumab have been added into the lymphoma treatment armamentarium. Currently, only the antiCD20 directed antibodies rituximab and obinutuzumab have approved indications for FL, while polatuzumab and tafasitamab have approvals in relapsed DLBCL in combination with bendamustine/rituximab and lenalidomide, respectively.

Polatuzumab is an anti-CD79 antibody conjugated to the cytotoxic molecule monomethyl auristatin $\mathrm{E}$ (MMAE) which was initially studied in combination with rituximab in both DLBCL and FL in the ROMULUS study [80]. In the FL cohort (25\% of patients were refractory to rituximab) the ORR and CR rates were $70 \%$ and $45 \%$, respectively with a median PFS of 15 months. However, $95 \%$ of the patients developed peripheral neuropathy during the course of the study, with a high rate at the $2.4 \mathrm{mg} / \mathrm{kg}$ dosing. Hence, a lower dose was recommended $(1.8 \mathrm{mg} / \mathrm{kg}$ dosing) for future clinical trials. Polatutumab was studied in combination with BR versus BR alone in patients in rel/ref FL in the GO29365 trial [81]. Similar efficacy was seen with the ORR and CR rates of $77 \%$ and $69 \%$, respectively in the BR + polatuzumab cohort and $73 \%$ and $63 \%$, in the BR cohort with a median PFS of 17 months in each cohort. Polatuzumab has also been studied in combination with lenalidomide and obinutuzumab in phase Ib/II trial and demonstrated an ORR and CR rate of $76 \%$ and $65 \%$, respectively [82]. Of note, $71 \%$ of pts who were refractory to their prior treatment achieved a CR, demonstrating the high activity of this combination in rel/ref FL.

Tafasitamab is a humanized antibody containing a hybrid IgG1/2 Fc domain directed against CD19 with enhanced antibody-dependent cellular cytotoxicity and antibody-dependent phagocytosis. Tafasitamab is currently approved for the treatment of rel/ref DLBCL in combination with lenalidomide based on the results of the L-MIND trial which demonstrated an ORR and CR rate of $43 \%$ and $18 \%$ with the most frequent grade 3 or higher treatment-emergent AEs being neutropenia (48\%), thrombocytopenia (17\%) and febrile neutropenia (12\%) [83]. A phase III placebo-controlled study (lnMIND) of tafasitamab in combination with rituximab and lenalidomide is currently recruiting patients with rel/ref FL and
MZL with an anticipated primary completion date of June of 2023(NCT04680052).

\section{Checkpoint blockade}

Checkpoint blockade has shown mixed results in FL patients. Initial preclinical studies demonstrated that PD-1 expression is significantly upregulated on the surface of the peripheral blood and intratumoral CD4+ and $\mathrm{CD} 8+\mathrm{T}$ cells in FL patients and PD-1 blockade resulted in significantly enhanced $\mathrm{T}$ cell function, thus confirming the immunomodulatory role of the PD-1/PDL-1 axis in FL-associated $\mathrm{T}$ cells [84]. A phase II study evaluated the activity of the combination of the PD-1 blocking antibody pembrolizumab with rituximab in patients after one or more prior lines of therapy who were not rituximab refractory [85]. Pembrolizumab was given at $200 \mathrm{mg}$ every 3 weeks for up to 16 cycles while rituximab was given weekly for the first cycle of treatment. Of 25 patients evaluable for efficacy, the ORR and CR rates were $64 \%$ and $48 \%$, respectively, although it should be noted that only $50 \%$ of enrolled patients had a lymphoma burden that met the GELF criteria. All immune-related AEs were either grade 1 or 2 , but five patients discontinued therapy because of recurrent immune-related AEs. Baseline tumor PDL1 levels were not associated with response. The phase II Checkmate 140 study investigating nivolumab monotherapy ( $3 \mathrm{mg} / \mathrm{kg}$ every 2 weeks) in rel/ref FL showed an ORR of only $4 \%$ with median PFS of 2.2 months [86]. These results suggest that combination strategies with other immune stimulatory therapies will likely be required to realize the potential benefit of checkpoint blockade in rel/ref FL.

Despite the increased responses of combined PD-1/ CTLA4 blockade in certain malignancies, a phase1b study of combining nivolumab and ipilimumab in $\mathrm{rel} / \mathrm{ref}$ lymphoma and myeloma ( $n=65$ total, 5 with FL) showed an ORR and CR rate of $19 \%$ and $6 \%$, respectively, in the B-NHL patients $(n=16)$ with only one response in the FL patients[87]. As expected, there was higher toxicity compared to past experience with nivolumab monotherapy. These results show that combined PD-1/CTLA4 is unlikely to have a role in FL immunotherapy.

Given the role of PI3K inhibition in promoting a more favorable immune microenvironment by a combination of immunomodulatory effects including depletion of Treg cells and improved macrophage inflammatory M1 to immunosuppressive M2 ratio [88, 89], another area of active interest is combining PI3Ki with immune checkpoint blockade. A phase I study with copanlisib with either nivolumab, a PD-1 blocking antibody, or with both nivolumab and ipilimumab, an antibody that blocks the inhibitory protein CTLA-4 on T cells in various cancers (NCT03502733) was initiated but subsequently 
suspended due to toxicity. A phase I study combining duvelisib and nivolumab (NCT03892044) which includes patients with transformed FL and CLL is ongoing as well as another study is investigating pembrolizumab either alone or with idelalisib or ibrutinib in patients with rel/ ref low-grade B-NHL or CLL (NCT02332980). Given the reduced autoimmune toxicity seen with umbralisib relative to the other PI3K inhibitors, combining umbralisib with immune checkpoint blockade may provide a more favorable toxicity profile while still potentiating an immune-mediated anti-lymphoma response. Umbralisib is currently being combined with pembrolizumab in rel/ ref B-NHL and CLL (NCT03283137).

Other clinical trials investigating combination strategies combining immune checkpoint blockade with rituximab and obinutuzumab (NCT03401853), rituximab, and lenalidomide (NCT02446457), ibrutinib (NCT02329847), and the bispecific anti-CD20 antibody mosunetuzumab (see cellular therapy section, NCT02500407) are currently ongoing.

CD47 is a surface protein expressed on nearly all cancers including lymphomas that provides an antiphagocytic signal to enable cancer cells to evade macrophage-mediated killing [90]. CD47 antibodies not only induce apoptosis but also produce $\mathrm{T}$ cell responses by enhancing macrophage antigen presentation. Magrolimab (Hu5F9-G4) is a CD47 blocking antibody that is currently being studied in combination with rituximab in a phase $\mathrm{Ib} / 2$ trial of FL and DLBCL. Preliminary results from the phase Ib portion showed an ORR and CR rate of $71 \%$ and $43 \%$ in the FL cohort [91]. The treatment was well tolerated with the most common side effects being chills (41\%), headache (41\%), anemia (41\%), and infusionrelated reactions (36\%). The phase II portion of the study is currently recruiting (NCT02953509). A phase I study of magrolimab in combination with obinutuzumab and venetoclax in indolent lymphomas is currently recruiting patients as well (NCT04599634). Other CD47 blocking antibodies currently in clinical trials enrolling patients with lymphoma include TTI-622 (NCT03530683) and ALX148 (NCT03013218).

\section{Cellular therapies}

\section{Chimeric antigen receptor T cell (CART) therapy}

CD19 CART therapy has revolutionized the management of relapsed lymphoid malignancies offering potentially curative therapy to patients who were previously deemed incurable by contemporary therapies. Axicabtagene ciloleucel (axi-cel, Yescarta) received FDA approval in 2017 for $\mathrm{rel} / \mathrm{ref}$ DLBCL after two prior lines of treatment based on the ZUMA-1 trial that showed an ORR and CR rate of $83 \%$ and $58 \%$ with a median PFS of 5.9 months [92]. Similarly, tisagenlecleucel (tisa-cel, Kymriah) received approval in 2018 based on results of the JULIET trial showing an ORR and CR rate of $52 \%$ and $40 \%$ with a relapse-free survival of $65 \%$ at 12 months. Both therapies have since been investigated in FL with impressive results.

Axicabtagene ciloleucel The ZUMA-5 trial investigating axi-cel in indolent lymphomas enrolled patients with either FL or MZL after failing at least 2 prior lines of therapy (including an anti-CD20 therapy and an alkylating agent) with preliminary results recently reported at the 2020 ASH annual conference [93]. The study enrolled 146 patients, 124 of whom had rel/ref FL, many with highrisk disease including $55 \%$ of patients with progression of disease within 24 months of initial therapy (POD24) and $68 \%$ of who were refractory to their prior treatment. Axicel showed an ORR and CR rate of $94 \%$ and $60 \%$, respectively in the FL patients with comparable responses across key risk groups. At data cutoff, $64 \%$ of FL patients had ongoing responses. Grade $\geq 3$ cytokine release syndrome (CRS) and neurologic events only occurred in 6\% and 15\% of FL patients with one CRS-related death. In March of 2021, the FDA granted accelerated approval for axi-cel for patients with rel/ref FL after two or more prior lines of therapy.

Tisagenlecleucel The ELARA study investigated tis-cel in patients with FL who received 2 prior lines of therapy, with the previous relapse within 6 months from the prior therapy or relapse after autologous hematopoietic cell transplant (auto-HCT) being other required criteria for enrollment [94]. Patients in this trial were also high-risk with $60 \%$ of patients with POD24 and $77 \%$ who were refractory to their last treatment. The ORR and CR rates were $82.7 \%$ and $65.4 \%$ in the intent to treat population with comparable responses across all prognostic groups. At a median follow-up of 9.9 months, median PFS had not been reached. There were no grade $\geq 3$ CRS and only $2 \%$ had grade $\geq 3$ neurologic events, all of which recovered which was consistent with the overall lower rate of CRS events in tisa-cel compared to axi-cel based on prior clinical experience. FDA approval has not yet been granted for tisa-cel at the time of this writing. Long-term follow-up is needed to evaluate the durability of response with CART therapy in rel/ref FL especially high-risk disease groups.

\section{Bispecific T cell engager (BiTe) antibody therapy}

BiTes are antibodies composed of two distinct antibody chains, one which recognizes an epitope present on $\mathrm{T}$ cells and the other of which is directed to an epitope on the target cell of interest resulting in direct cell-mediated toxicity by the cross-linked $\mathrm{T}$ cell to the tumor cell [95]. Although BiTes are not currently approved for FL at that 


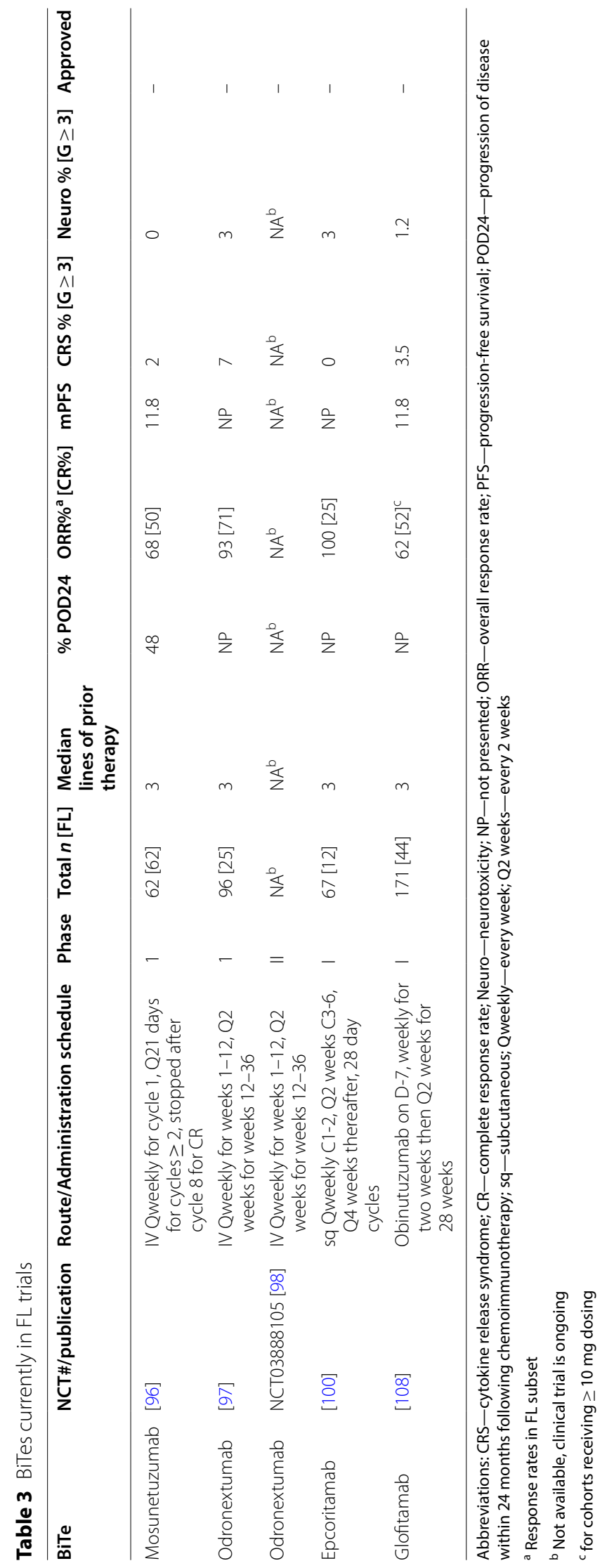


time of this writing, the preliminary results with these agents in highly pre-treated FL appear promising in early phase clinical trials (Table 3). Larger efficacy studies are currently ongoing.

Mosunetuzumab Mosunetuzumab is a CD20 directed BiTe that has been investigated in DLBCL and FL with updated results recently reported from a phase I dose escalation study in FL [96]. After weekly step-up administration during the first cycle, infusions were continued every 21 days for 8 cycles in patients who achieve CR or was continued for up to 17 cycles for patients who had stable or partial responses. The median number of prior treatments was 3 with $48 \%$ of patients with POD24 and $6 \%$ of patients who had prior CART therapy. The ORR and CR rate was $68 \%$ and $50 \%$, respectively. At a median follow-up of 14.4 months, $62 \%$ of patients remained in remission with a median PFS of 11.8 months. SAEs occurred in $35 \%$ of patients, but only $21 \%$ of patients had CRS (one with grade $\geq 3$ ) and $45 \%$ had neurologic $\mathrm{AE}$ (none with grade $\geq 3$ ). The FDA has granted breakthrough therapy designation for mosunetuzumab in FL after 2 prior lines of therapy.

Odronextamab Odronextamab (REGN1979), a CD20/ $\mathrm{CD} 3 \mathrm{BiTe}$, is an IgG4 antibody that is modified to reduce binding to the Fc receptor which has been studied in rel/ ref B cell NHL [97]. Odronextamab was given every week for a total of 12 weeks followed by biweekly dosing for 12 more doses. Ninety-six patients were enrolled (25 with FL), 12 patients with prior CART. The CRS rate was $57 \%$ $(n=7$ with grade $\geq 3)$. Grade 3 or higher neurotoxicity occurred in two patients [97]. The trial was suspended temporarily due to a patient's death from TLS for a protocol amendment. Responses were evaluated over a broad range of dosages with dosage-dependent responses seen. With treatment $\geq 80 \mathrm{mg}$, the FL cohort demonstrated an ORR of $95.5 \%$ (CR rate $=77.3 \%)$ with $\geq 5 \mathrm{mg}$ [97]. A global phase II study is currently enrolling 5 separate disease cohorts of rel/ref NHLs, one of which is rel/ref FL [98]. However, at the time of this writing, a temporary hold was placed on both clinical trials due to a higher than anticipated rate of grade $\geq 3$ CRS with a protocol amendment awaited to mitigate this risk.

Epcoritamab Epcoritamab (GEN3013), a CD20/CD3 $\mathrm{BiTe}$, is an IgG1 antibody that is unique in that it is administered subcutaneously rather than IV [99]. In preclinical models, subcutaneous administration demonstrated similar bioavailability and B cell depletion as IV administration but with lower plasma cytokine levels and was hypothesized to result in less CRS but with the same responses in patients [99]. Updated results of a dose esca- lation trial of epcoritamab administered subcutaneously in the outpatient setting in various lymphoma subtypes (18\% with FL) were presented at the 2020 ASH conference [100]. The ORR and CR rate for FL patients $(n=8)$ was $100 \%$ and $25 \%$, respectively. There were no grade $\geq 3$ CRS events and only $3 \%$ had grade $\geq 3$ neurologic events.

Glofitamab Glofitamab (RO7082859) is a BiTE with a novel structure with bivalency for CD20 on lymphoma cells and monovalency for CD3 on T cells. In preclinical models of DLBCL, glofitamab had improved tumor cell kill compared to other bispecific antibodies [101]. Based on preclinical studies, obinutuzumab was given seven days prior to glofitamab infusion in a phase I study of rel/ref NHLs ( $n=171, \sim 26 \%$ were FL) for peripheral and tissue B cell depletion to reduce the severity of CRS. In addition, a Bayesian modified continuous reassessment method was used for dose escalation. Efficacy was found to be dosage dependent in all NHL histologies with a higher ORR and $\mathrm{CR}$ rate for patients receiving $\geq 10 \mathrm{mg}$ of $63.3 \%$ and $36.8 \%$ $(n=98)$ versus $53.8 \%$ and $52.0 \%$ for all dosing cohorts $(n=171)$. At the recommended phase 2 dosing (RP2D) of the weekly ramp of $2.5 / 10 / 30 \mathrm{mg}$, the ORR and CR rate for all histologies was $71.4 \%$ and $64.3 \%$. The response rates in the FL cohort were dose dependent with an ORR and CR rate of $69 \%$ and $58.6 \%$ for the $\geq 10 \mathrm{mg}$ cohorts $(n=29)$ and $70.5 \%$ and $47.7 \%$ for all FL dosing cohorts $(n=44)$. Although there was a high overall rate of CRS (50.3\%), the incidence of grade $\geq 3$ CRS was only $3.5 \%$. As expected, CRS increased with dose but decreased in later cycles. Neurotoxicity was overall uncommon (3.5\%) with grade $\geq 3$ being only $1.8 \%$. Several combination trials with glofitamab are currently planned for rel/ref NHL, including in combination with R-CHOP (NCT03467373) and or with polatuzumab or atezolizumab (NCT03533283).

\section{Approach to the POD24 patient}

Patients with FL who progress within 24 months after completing first-line chemoimmunotherapy are defined as POD24. POD24 occurs in approximately 1 out of every 5 patients receiving $\mathrm{R}-\mathrm{CHOP}$ as their primary therapy and is prognostically significant in this setting with a 5 year OS of $50 \%$ compared to $90 \%$ for non-POD24 patients [102]. Although validation of the predictive value of this endpoint in the case of other primary therapies, such as R2, is still needed, it is likely that progression after these other therapies also represents a high-risk disease that requires special approaches to achieving more durable responses after second-line therapy. The optimal management of the POD24 is an area of active investigation.

Escalation of second-line therapy with a consolidative auto-HCT in the patient fit for transplant has been 
a common approach. Although there are currently no randomized clinical trials to support this, studies suggest survival benefit of this approach in certain circumstances. A retrospective study using data from the Center for the International Blood and Bone marrow Transplant Research (CIMBTR) database and National Lymphocare Study (NCLS) compared 175 patients undergoing autoHCT to 174 patients who did not within 2 years of treatment failure. Although this study did not find a difference in OS between these two groups, there was an improvement in 5 year OS (73\% vs $60 \%)$ in favor of auto-HCT when looking at the subset of patients within one year of front-line treatment failure. In another analysis of the outcomes of POD24 patients enrolled on two German low-grade lymphoma clinical trials (GSLG1996 GSLG2000), there was a 5 year OS benefit among patients who received auto-HCT consolidation after second-line cytoreduction versus patients who underwent successful cytoreduction but did not undergo auto-HCT. The continued survival benefit of auto-HCT in the age of newer treatment modalities, such as obinutuzumab, immunomodulators, and PI3K inhibitors, is unclear and will have to be addressed with future outcome studies with patients undergoing treatment in the current era.

A pressing question currently is whether there is an optimal second-line therapy to offer POD24 patients after first-line chemoimmunotherapy failure. This question is currently being addressed by the SWOG1608 phase II intergroup trial (NCT03269669) which randomizes patients who have progressed after first-line chemoimmunotherapy into one of three arms: obinutuzumab and umbralisib, obinutuzumab and lenalidomide, or obinutuzumab and chemoimmunotherapy (bendamustine for previous $\mathrm{R}-\mathrm{CHOP}$ or $\mathrm{R}-\mathrm{CHOP}$ for previous bendamustine). This trial is currently recruiting with an anticipated completion at the end of 2022 .

\section{Investigational approaches in Newly Diagnosed Advanced Stage FL}

The majority of patients who receive frontline therapy with either chemoimmunotherapy or R2 will have a relatively durable response to therapy with a median PFS of 69.5 months for BR and a 3 year PFS of $77 \%$ for R2 $[103,104]$. Long-term follow-up of the phase III PRIMA study compared patients who received rituximab maintenance therapy after chemoimmunotherapy (with either R-CHOP, R-CVP, or R-FCM) vs patients who did not receive maintenance rituximab showed an impressive median PFS of 10.5 years vs 4.1 years, respectively [105]. Further improvement on these already favorable results will require significantly long follow-up if unselected patient populations are recruited in trials. Targeting higher risk populations for trial enrollment has been difficult given the smaller number of these high-risk patients and the need for more accurate biomarkers predicting these high-risk patients at the start of treatment. Many past and current investigations into optimizing frontline therapy have focused on either incorporating novel treatments into induction and/or maintenance therapy or delivering less therapy with the hope of achieving the same durable responses.

The GALLIUM study investigated the benefit of obinutuzumab versus rituximab in combination with chemotherapy and found an improved estimated 3 year PFS (80.0\% vs $73.3 \%)$ although no improvement in OS with a slightly higher frequency of grade $\geq 3 \mathrm{AE}(74.6 \%$ vs $67.8 \%)$. It is important to note that all patients on this trial went on to receive maintenance obinutuzumab or rituximab so it is unclear if this same benefit would be seen without the addition of maintenance.

A recent randomized phase II trial incorporating bortezomib into BR induction (BR-R) either with rituximab maintenance or lenalidomide plus rituximab maintenance failed to demonstrate any additional benefit of incorporating either of these treatments to standard BR induction/rituximab maintenance therapy [106]. An ongoing phase II trial is investigating the addition of obinutuzumab with lenalidomide in the frontline setting to take advantage of the NK cell activating potential of lenalidomide to increase the ADCC of obinutuzumab [107]. Preliminary results are encouraging with an ORR and CR rate of $94 \%$ and $87 \%$ with a 2 year PFS of $96 \%$ [107]. Several clinical trials are currently ongoing using novel agents with anti-CD20 monoclonal antibodies in the frontline setting such as umbralisib with either rituximab (NCT03919175) or ublituximab (NCT03828448, NCT04508647), and tazemetostat with R-CHOP (NCT02889523).

Risk-adapted approaches are currently ongoing to evaluate the possibility of either de-escalation or escalation of therapy based on end of treatment responses. An ongoing Italian FOLL12 study (NCT02063685) is addressing if the end of induction therapy response as assessed by PET or MRD status can be used to either escalate or de-escalate maintenance therapy to ultimately improve upon PFS compared to standard rituximab maintenance therapy. Patients in the standard therapy arm will go on to receive rituximab maintenance after chemoimmunotherapy while patients in the experimental arm will be randomized into three groups: A) MRD negative, PET negative patients will be observed, B) MRD positive and PET negative patients will continue with rituximab maintenance, C) MRD positive and PET-positive patients will undergo consolidative radioimmunotherapy with [90]Y ibritumumab tiuxetan and rituximab maintenance. This 
trial has completed accrual and awaiting data maturation. UK and Australian PET response adapted therapy trial (PETReA) will randomize patients based on their end of induction therapy PET response: patients with negative PET will be randomized either to observation or maintenance rituximab and patients with positive PET will be randomized to maintenance rituximab or maintenance rituximab plus lenalidomide. This trial was opened in May of 2018 with a recruitment goal of around 1000 patients.

\section{Future perspectives}

Although the majority of patients with advanced FL who require treatment are expected to have relatively good long-term outcomes based on current treatment approaches, there is still around 20\% of patients who have a persistent relapsing course with very difficult to treat disease. This subset of patients needs to be prioritized for experimental therapies and investigational approaches. The SWOG1608 will likely address the approach for POD24 patients in the second-line setting. However, these patients will eventually relapse. Conventionally, allogeneic HCT was the only curative option in these high-risk patients but with the advent of several newer therapies in the second and later line setting, including CART therapy and the BiTes, the sequential use of therapies and the decision of when to pursue cellular therapy has become much more complex. Another important question of whether auto-HCT will continue to play a significant role in patients with POD24 or will it be supplanted by CART in the near future needs to be answered. A randomized clinical trial comparing auto-HCT to axi-cel therapy in this patient population, analogous to the ongoing ZUMA-7 trial in DLBCL, is warranted. Likewise, given the $\mathrm{CR}$ rate with the early BiTE therapy trials in heavily treated FL patients, these treatments will also likely play a role in the POD24 patient as well.

\section{Conclusions}

Despite a better understanding of the genetic, epigenetic, and immunological landscape of FL, biomarkerdriven and personalized approaches have remained elusive in the front-line treatment of FL, with "one size fits all" chemoimmunotherapy still being the most common approach for front line advanced FL treatment. The efficacy of the EZH2 inhibitor tazemetostat in the EZH2 mutated patient in the relapsed patient was a significant step forward in biomarker-driven therapy in FL. It will be interesting to discover whether patients in this subgroup would be able to avoid chemoimmunotherapy in their upfront treatment of FL if tazemetostat has significant activity in this setting, especially if it could be given for a fixed duration. Similarly, other chemo-free regimens like umbralisib and ublituximab given for a fixed duration or in a response-driven fashion, as in NCT04508647, are attractive but these types of frontline studies will require several years of follow-up to demonstrate non-inferiority or superiority.

Although chemoimmunotherapy was the mainstay for the treatment of FL for a long time, the past decade has seen an exciting number of novel targeted and cellular therapies in FL. Current and future trials on the horizon will continue to identify innovative treatment approaches and will hopefully lead to better outcomes in the most difficult to treat patients with FL.

\section{Abbreviations \\ FL: Follicular Lymphoma; rel/ref: Relapsed/Refractory; NHL: Non-Hodgkin's lymphoma; Auto-HCT: Autologous hematopoietic stem cell transplant; CAR :Chimeric Antigen Receptor; BiTe: Bispecific T cell engager; Btk: Bruton's tyrosine kinase; ORR: Overall Response Rate; CR: Complete Response; PFS: Progression-Free Survival; OS: Overall Survival; R2: Lenalidomide (Revlimid) and rituximab.}

\section{Acknowledgements \\ None.}

Authors' contributions

WH and NE were involved in the conception, design, and manuscript preparation. Both authors approved the final version of the manuscript.

Funding

None.

Availability of data and material

Not applicable.

\section{Declarations}

Ethics approval and consent to participate

Not applicable.

Consent for publication

Not applicable.

Competing interests

$\mathrm{WH}$ and NE has no relevant COI pertaining to the manuscript.

Author details

${ }^{1}$ Division of Hematology, Department of Medicine, The James Cancer Hospital and Solove Research Institute, The Ohio State University, 460 W 10th Ave,

Columbus, OH 43210, USA. ${ }^{2}$ The Ohio State University Comprehensive Cancer Center, 1110 E Lincoln Tower, 1800 Cannon Drive, Columbus, OH 43210, USA.

Received: 26 April 2021 Accepted: 4 June 2021

Published online: 30 June 2021

\footnotetext{
References

1. Swerdlow SH, Campo E, Pileri SA, Harris NL, Stein H, Siebert R, et al. The 2016 revision of the World Health Organization classification of lymphoid neoplasms. Blood. 2016;127(20):2375-90.

2. Freedman A. Follicular lymphoma: 2018 update on diagnosis and management. Am J Hematol. 2018;93(2):296-305.
} 
3. Armitage JO, Weisenburger DD. New approach to classifying non-Hodgkin's lymphomas: clinical features of the major histologic subtypes. Non-Hodgkin's Lymphoma Classification Project. J Clin Oncol. 1998;16(8):2780-95.

4. Schmitt C, Balogh B, Grundt A, Buchholtz C, Leo A, Benner A, et al. The $\mathrm{bcl}-2 / \mathrm{lgH}$ rearrangement in a population of 204 healthy individuals: occurrence, age and gender distribution, breakpoints, and detection method validity. Leuk Res. 2006;30(6):745-50.

5. Summers KE, Goff LK, Wilson AG, Gupta RK, Lister TA, Fitzgibbon J. Frequency of the $\mathrm{Bcl}-2 / \mathrm{lgH}$ rearrangement in normal individuals: implications for the monitoring of disease in patients with follicular lymphoma. J Clin Oncol. 2001;19(2):420-4.

6. Campo E, Swerdlow SH, Harris NL, Pileri S, Stein H, Jaffe ES. The 2008 WHO classification of lymphoid neoplasms and beyond: evolving concepts and practical applications. Blood. 2011;117(19):5019-32.

7. Okosun J, Bodor C, Wang J, Araf S, Yang CY, Pan C, et al. Integrated genomic analysis identifies recurrent mutations and evolution patterns driving the initiation and progression of follicular lymphoma. Nat Genet. 2014;46(2):176-81.

8. Sugimoto T, Watanabe T. Follicular lymphoma: the role of the tumor microenvironment in prognosis. J Clin Exp Hematop. 2016;56(1):1-19.

9. Dave SS, Wright G, Tan B, Rosenwald A, Gascoyne RD, Chan WC et al. Prediction of survival in follicular lymphoma based on molecular features of tumor-infiltrating immune cells. N Engl J Med. 2004;351(21):2159-69.

10. Farinha P, Masoudi H, Skinnider BF, Shumansky K, Spinelli JJ, Gill K, et al. Analysis of multiple biomarkers shows that lymphoma-associated macrophage (LAM) content is an independent predictor of survival in follicular lymphoma (FL). Blood. 2005;106(6):2169-74.

11. Lee AM, Clear AJ, Calaminici M, Davies AJ, Jordan S, MacDougall F, et al. Number of CD4+ cells and location of forkhead box protein P3-positive cells in diagnostic follicular lymphoma tissue microarrays correlates with outcome. J Clin Oncol. 2006;24(31):5052-9.

12. Carreras J, Lopez-Guillermo A, Fox BC, Colomo L, Martinez A, Roncador $G$, et al. High numbers of tumor-infiltrating FOXP3-positive regulatory $T$ cells are associated with improved overall survival in follicular lymphoma. Blood. 2006;108(9):2957-64.

13. Smeltzer JP, Jones JM, Ziesmer SC, Grote DM, Xiu B, Ristow KM, et al. Pattern of CD14+ follicular dendritic cells and PD1+T cells independently predicts time to transformation in follicular lymphoma. Clin Cancer Res. 2014;20(11):2862-72.

14. Yang ZZ, Kim HJ, Villasboas JC, Price-Troska T, Jalali S, Wu H, et al. Mass cytometry analysis reveals that specific intratumoral CD4(+) T cell subsets correlate with patient survival in follicular lymphoma. Cell Rep. 2019;26(8):2178-93.

15. Gribben JG, Fowler N, Morschhauser F. Mechanisms of action of lenalidomide in B-cell non-Hodgkin lymphoma. J Clin Oncol. 2015;33(25):2803-11.

16. Lopez-Girona A, Mendy D, Ito T, Miller K, Gandhi AK, Kang J, et al. Cereblon is a direct protein target for immunomodulatory and antiproliferative activities of lenalidomide and pomalidomide. Leukemia. 2012;26(11):2326-35.

17. Ito T, Ando H, Suzuki T, Ogura T, Hotta K, Imamura Y, et al. Identification of a primary target of thalidomide teratogenicity. Science. 2010;327(5971):1345-50.

18. Lu G, Middleton RE, Sun H, Naniong M, Ott CJ, Mitsiades CS, et al. The myeloma drug lenalidomide promotes the cereblon-dependent destruction of Ikaros proteins. Science. 2014;343(6168):305-9.

19. Verhelle D, Corral LG, Wong K, Mueller JH, Moutouh-de Parseval L, Jensen-Pergakes K, et al. Lenalidomide and CC-4047 inhibit the proliferation of malignant $\mathrm{B}$ cells while expanding normal $C D 34+$ progenitor cells. Cancer Res. 2007;67(2):746-55.

20. Zhang LH, Kosek J, Wang M, Heise C, Schafer PH, Chopra R. Lenalidomide efficacy in activated B-cell-like subtype diffuse large B-cell lymphoma is dependent upon IRF4 and cereblon expression. Br J Haematol. 2013;160(4):487-502.

21. Hayashi T, Hideshima T, Akiyama M, Podar K, Yasui H, Raje N, et al. Molecular mechanisms whereby immunomodulatory drugs activate natural killer cells: clinical application. Br J Haematol. 2005;128(2):192-203.
22. Ramsay AG, Clear AJ, Kelly G, Fatah R, Matthews J, Macdougall F, et al. Follicular lymphoma cells induce T-cell immunologic synapse dysfunction that can be repaired with lenalidomide: implications for the tumor microenvironment and immunotherapy. Blood. 2009;114(21):4713-20.

23. Henry JY, Labarthe MC, Meyer B, Dasgupta P, Dalgleish AG, Galustian C. Enhanced cross-priming of naive CD8+T cells by dendritic cells treated by the IMiDs(R) immunomodulatory compounds lenalidomide and pomalidomide. Immunology. 2013;139(3):377-85.

24. Leonard JP, Jung SH, Johnson J, Pitcher BN, Bartlett NL, Blum KA, et al. Randomized trial of lenalidomide alone versus lenalidomide plus rituximab in patients with recurrent follicular lymphoma: CALGB 50401 (Alliance). J Clin Oncol. 2015;33(31):3635-40.

25. Leonard JP, Trneny M, Izutsu K, Fowler NH, Hong X, Zhu J, et al. AUGMENT: a phase III study of lenalidomide plus rituximab versus placebo plus rituximab in relapsed or refractory indolent lymphoma. J Clin Oncol. 2019;37(14):1188-99.

26. Andorsky DJ, Coleman M, Yacoub A, Melear JM, Fanning SR, Kolibaba K, et al. MAGNIFY: phase IIIb interim analysis of induction R2 followed by maintenance in relapsed/refractory indolent non-Hodgkin lymphoma. J Clin Oncol. 2019;37(15_suppl):7513.

27. Golay J, Da Roit F, Bologna L, Ferrara C, Leusen JH, Rambaldi A, et al. Glycoengineered CD20 antibody obinutuzumab activates neutrophils and mediates phagocytosis through CD16B more efficiently than rituximab. Blood. 2013;122(20):3482-91.

28. Fowler NH, Nastoupil LJ, Chin C, Strati P, Hagemeister FB, Fayad LE, et al. A phase I/II study of lenalidomide plus obinutuzumab in relapsed indolent lymphoma. Blood. 2019;134(Supplement_1):348.

29. Morschhauser F, Le Gouill S, Feugier P, Bailly S, Nicolas-Virelizier E, Bijou $F$, et al. Obinutuzumab combined with lenalidomide for relapsed or refractory follicular B-cell lymphoma (GALEN): a multicentre, single-arm, phase 2 study. Lancet Haematol. 2019;6(8):e429-37.

30. Hemmings BA, Restuccia DF. The PI3K-PKB/Akt pathway. Cold Spring Harb Perspect Biol. 2015;7(4):a011189.

31. Vanhaesebroeck B, Guillermet-Guibert J, Graupera M, Bilanges B. The emerging mechanisms of isoform-specific PI3K signalling. Nat Rev Mol Cell Biol. 2010;11(5):329-41.

32. Okkenhaug K, Turner M, Gold MR. PI3K signaling in B Cell and T cell biology. Front Immunol. 2014;5:557.

33. Pauls SD, Lafarge ST, Landego I, Zhang T, Marshall AJ. The phosphoinositide 3-kinase signaling pathway in normal and malignant B cells: activation mechanisms, regulation and impact on cellular functions. Front Immunol. 2012;3:224.

34. Jou ST, Carpino N, Takahashi Y, Piekorz R, Chao JR, Carpino N, et al. Essential, nonredundant role for the phosphoinositide 3-kinase p110delta in signaling by the B-cell receptor complex. Mol Cell Biol. 2002;22(24):8580-91.

35. Foubert P, Kaneda MM, Varner JA. PI3Kgamma activates integrin alpha4 and promotes immune suppressive myeloid cell polarization during tumor progression. Cancer Immunol Res. 2017;5(11):957-68.

36. Gopal AK, Kahl BS, de Vos S, Wagner-Johnston ND, Schuster SJ, Jurczak WJ, et al. PI3Kdelta inhibition by idelalisib in patients with relapsed indolent lymphoma. N Engl J Med. 2014;370(11):1008-18.

37. Greenwell IB, Ip A, Cohen JB. PI3K inhibitors: understanding toxicity mechanisms and management. Oncology (Williston Park). 2017:31(11):821-8.

38. Cuneo A, Barosi G, Danesi R, Fagiuoli S, Ghia P, Marzano A, et al. Management of adverse events associated with idelalisib treatment in chronic lymphocytic leukemia and follicular lymphoma: a multidisciplinary position paper. Hematol Oncol. 2019;37(1):3-14.

39. Dreyling M, Morschhauser F, Bouabdallah K, Bron D, Cunningham D, Assouline SE, et al. Phase II study of copanlisib, a PI3K inhibitor, in relapsed or refractory, indolent or aggressive lymphoma. Ann Oncol. 2017;28(9):2169-78.

40. Dreyling M, Santoro A, Mollica L, Leppa S, Follows G, Lenz G, et al. Longterm safety and efficacy of the PI3K inhibitor copanlisib in patients with relapsed or refractory indolent lymphoma: 2-year follow-up of the CHRONOS-1 study. Am J Hematol. 2019;95(4):362-71.

41. Flinn IW, Miller CB, Ardeshna KM, Tetreault S, Assouline SE, Mayer J, et al. DYNAMO: a phase II study of Duvelisib (IPI-145) in patients with refractory indolent non-Hodgkin lymphoma. J Clin Oncol. 2019;37(11):912-22. 
42. Janovska P, Normant E, Miskin H, Bryja V. Targeting Casein kinase 1 (CK1) in hematological cancers. Int J Mol Sci. 2020;21(23):9026.

43. Maharaj K, Powers JJ, Achille A, Mediavilla-Varela M, Gamal W, Burger $\mathrm{KL}$, et al. The dual PI3Kdelta/CK1epsilon inhibitor umbralisib exhibits unique immunomodulatory effects on CLL T cells. Blood Adv. 2020;4(13):3072-84.

44. Fowler NH, Samaniego F, Jurczak W, Ghosh N, Derenzini E, Reeves JA, et al. Umbralisib, a dual PI3K $/$ CK1 $\varepsilon$ inhibitor in patients with relapsed or refractory indolent lymphoma. J Clin Oncol. 2021. https://doi.org/10. 1200/jco.20.03433.

45. Phillips TJ, Forero-Torres A, Sher T, Diefenbach CS, Johnston P, Talpaz $\mathrm{M}$, et al. Phase 1 study of the PI3K $\delta$ inhibitor INCB040093 \pm JAK1 inhibitor itacitinib in relapsed/refractory B-cell lymphoma. Blood. 2018;132(3):293-306.

46. Hillmann P, Fabbro D. PI3K/mTOR pathway inhibition: opportunities in oncology and rare genetic diseases. Int J Mol Sci. 2019;20(22):5792.

47. Phillips TJ, Michot JM, Ribrag V. Can next-generation PI3K inhibitors unlock the full potential of the class in patients with B-cell lymphoma? Clin Lymphoma Myeloma Leuk. 2021;21(1):8-20.

48. Smith SM, Pitcher BN, Jung SH, Bartlett NL, Wagner-Johnston N, Park SI, et al. Safety and tolerability of idelalisib, lenalidomide, and rituximab in relapsed and refractory lymphoma: the Alliance for Clinical Trials in Oncology A051201 and A051202 phase 1 trials. Lancet Haematol. 2017:4(4):e176-82.

49. Zinzani PL, Leppä S, Santoro A, Pedersen M, Buvaylo V, Hiemeyer F, Childs BH, Matasar MJ, editors. Feasibility of combining the phosphatidylinositol 3-kinase (pi3k) inhibitor copanlisib with rituximab (r)-based immunochemotherapy in patients (pts) with relapsed indolent nonHodgkin lymphoma (inhl). EHA. 2020.

50. Flinn IW, Cherry MA, Maris MB, Matous JV, Berdeja JG, Patel M. Combination trial of duvelisib (IPI-145) with rituximab or bendamustine/rituximab in patients with non-Hodgkin lymphoma or chronic lymphocytic leukemia. Am J Hematol. 2019;94(12):1325-34.

51. Lunning M, Vose J, Nastoupil L, Fowler N, Burger JA, Wierda WG, et al. Ublituximab and umbralisib in relapsed/refractory B-cell non-Hodgkin lymphoma and chronic lymphocytic leukemia. Blood. 2019;134(21):1811-20.

52. Barr PM, Smith SD, Roschewski MJ, O'Brien SM, Sharman JP, Melear JM, et al. Acalabrutinib combined with PI3K $\delta$ inhibitor ACP-319 in patients (pts) with relapsed/refractory (R/R) B-cell malignancies. J Clin Oncol. 2018;36(15_suppl):7518.

53. Sermer D, Pasqualucci L, Wendel HG, Melnick A, Younes A. Emerging epigenetic-modulating therapies in lymphoma. Nat Rev Clin Oncol. 2019;16(8):494-507.

54. Dominguez PM, Teater M, Chambwe N, Kormaksson M, Redmond D, Ishii J, et al. DNA methylation dynamics of germinal center B cells are mediated by AID. Cell Rep. 2015;12(12):2086-98.

55. Morin RD, Mendez-Lago M, Mungall AJ, Goya R, Mungall KL, Corbett RD, et al. Frequent mutation of histone-modifying genes in non-Hodgkin lymphoma. Nature. 2011;476(7360):298-303.

56. Araf S, Okosun J, Koniali L, Fitzgibbon J, Heward J. Epigenetic dysregulation in follicular lymphoma. Epigenomics. 2016;8(1):77-84.

57. Beguelin W, Popovic R, Teater M, Jiang Y, Bunting KL, Rosen M, et al. $E Z H 2$ is required for germinal center formation and somatic EZH2 mutations promote lymphoid transformation. Cancer Cell. 2013;23(5):677-92.

58. Peng D, Kryczek I, Nagarsheth N, Zhao L, Wei S, Wang W, et al. Epigenetic silencing of TH1-type chemokines shapes tumour immunity and immunotherapy. Nature. 2015;527(7577):249-53.

59. Italiano A, Soria JC, Toulmonde M, Michot JM, Lucchesi C, Varga A, et al. Tazemetostat, an EZH2 inhibitor, in relapsed or refractory B-cell non-Hodgkin lymphoma and advanced solid tumours: a first-in-human, open-label, phase 1 study. Lancet Oncol. 2018;19(5):649-59.

60. Morschhauser F, Tilly H, Chaidos A, McKay P, Phillips T, Assouline S, et al. Tazemetostat for patients with relapsed or refractory follicular lymphoma: an open-label, single-arm, multicentre, phase 2 trial. Lancet Oncol. 2020;21(11):1433-42.

61. Morishima S, Ishitsuka K, Izutsu K, Kusumoto S, Makiyama J, Utsunomiya $\mathrm{A}$, et al. First-in-human study of the EZH1/2 dual inhibitor valemetostat in relapsed or refractory non-Hodgkin lymphoma (NHL) — updated results focusing on adult T-cell leukemia-lymphoma (ATL). Blood. 2019;134(Supplement_1):4025.

62. Ogura M, Ando K, Suzuki T, Ishizawa K, Oh SY, Itoh K, et al. A multicentre phase II study of vorinostat in patients with relapsed or refractory indolent B-cell non-Hodgkin lymphoma and mantle cell lymphoma. Br J Haematol. 2014;165(6):768-76.

63. Bobrowicz M, Dwojak M, Pyrzynska B, Stachura J, Muchowicz A, Berthel E, et al. HDAC6 inhibition upregulates CD20 levels and increases the efficacy of anti-CD20 monoclonal antibodies. Blood. 2017;130(14):1628-38.

64. Chen R, Frankel P, Popplewell L, Siddiqi T, Ruel N, Rotter A, et al. A phase II study of vorinostat and rituximab for treatment of newly diagnosed and relapsed/refractory indolent non-Hodgkin lymphoma. Haematologica. 2015;100(3):357-62.

65. Oki Y, Buglio D, Fanale M, Fayad L, Copeland A, Romaguera J, et al. Phase I study of panobinostat plus everolimus in patients with relapsed or refractory lymphoma. Clin Cancer Res. 2013;19(24):6882-90.

66. Batlevi CL, Crump M, Andreadis C, Rizzieri D, Assouline SE, Fox S, et al. A phase 2 study of mocetinostat, a histone deacetylase inhibitor, in relapsed or refractory lymphoma. Br J Haematol. 2017;178(3):434-41.

67. Blum KA, Liu Z, Lucas DM, Chen P, Xie Z, Baiocchi R, et al. Phase I trial of low dose decitabine targeting DNA hypermethylation in patients with chronic lymphocytic leukaemia and non-Hodgkin lymphoma: doselimiting myelosuppression without evidence of DNA hypomethylation. Br J Haematol. 2010;150(2):189-95.

68. Moss JJ, Howard D, Van Meter E, Hayslip J. A phase I study of the combination of azacitidine, cyclophosphamide, vincristine, and rituximab in relapsed and refractory lymphoma. Blood. 2011;118(21):1624.

69. Chung J, Karkhanis V, Tae S, Yan F, Smith P, Ayers LW, et al. Protein arginine methyltransferase 5 (PRMT5) inhibition induces lymphoma cell death through reactivation of the retinoblastoma tumor suppressor pathway and polycomb repressor complex 2 (PRC2) silencing. J Biol Chem. 2013;288(49):35534-47.

70. Lu X, Fernando TM, Lossos C, Yusufova N, Liu F, Fontán L, et al. PRMT5 interacts with the BCL6 oncoprotein and is required for germinal center formation and lymphoma cell survival. Blood. 2018;132(19):2026-39.

71. Alinari L, Mahasenan KV, Yan F, Karkhanis V, Chung JH, Smith EM, et al. Selective inhibition of protein arginine methyltransferase 5 blocks initiation and maintenance of B-cell transformation. Blood. 2015;125(16):2530-43.

72. Chan-Penebre E, Kuplast KG, Majer CR, Boriack-Sjodin PA, Wigle TJ, Johnston $L D$, et al. A selective inhibitor of PRMT5 with in vivo and in vitro potency in MCL models. Nat Chem Biol. 2015;1 1(6):432-7.

73. Moreno V, Sepulveda JM, Vieito M, Hernandez-Guerrero T, Doger B, Saavedra O, et al. Phase I study of CC-90010, a reversible, oral BET inhibitor in patients with advanced solid tumors and relapsed/refractory non-Hodgkin's lymphoma. Ann Oncol. 2020;31 (6):780-8.

74. Abramson JS, Blum KA, Flinn IW, Gutierrez M, Goy A, Maris M, et al. BET inhibitor CPI-0610 Is well tolerated and induces responses in diffuse large B-cell lymphoma and follicular lymphoma: preliminary analysis of an ongoing phase 1 study. Blood. 2015;126(23):1491.

75. Davids MS, Roberts AW, Seymour JF, Pagel JM, Kahl BS, Wierda WG, et al. Phase I first-in-human study of venetoclax in patients with relapsed or refractory non-Hodgkin lymphoma. J Clin Oncol. 2017;35(8):826-33.

76. Zinzani PL, Flinn IW, Yuen SLS, Topp MS, Rusconi C, Fleury I, et al. Venetoclax-rituximab with or without bendamustine vs bendamustine-rituximab in relapsed/refractory follicular lymphoma. Blood. 2020;136(23):2628-37.

77. Ujjani CS, Lai C, Leslie LA, Ramzi P, Tan M, Wang S, et al. Ibrutinib and venetoclax in relapsed and refractory follicular lymphoma. Blood. 2020;136(Supplement 1):46-7.

78. Gopal AK, Schuster SJ, Fowler NH, Trotman J, Hess G, Hou JZ, et al. Ibrutinib as treatment for patients with relapsed/refractory follicular lymphoma: results from the open-label, multicenter, phase II DAWN study. J Clin Oncol. 2018;36(23):2405-12.

79. Bartlett NL, Costello BA, LaPlant BR, Ansell SM, Kuruvilla JG, Reeder $C B$, et al. Single-agent ibrutinib in relapsed or refractory follicular lymphoma: a phase 2 consortium trial. Blood. 2018;131(2):182-90.

80. Morschhauser F, Flinn IW, Advani R, Sehn LH, Diefenbach C, Kolibaba $K$, et al. Polatuzumab vedotin or pinatuzumab vedotin plus rituximab in patients with relapsed or refractory non-Hodgkin lymphoma: final 
results from a phase 2 randomised study (ROMULUS). Lancet Haematol. 2019;6(5):e254-65.

81. Sehn LH, Kamdar M, Herrera AF, McMillan A, Flowers C, Kim WS, et al. Randomized phase 2 trial of polatuzumab vedotin (pola) with bendamustine and rituximab (BR) in relapsed/refractory $(r / r) F L$ and DLBCL. J Clin Oncol. 2018;36(15_suppl):7507.

82. Diefenbach C, Kahl B, Banerjee L, McMillan A, Ramchandren R, Miall F, et al. Polatuzumab vedotin (Pola) + obinutuzumab (G) and lenalidomide (Len) in patients (pts) with relapsed/refractory (R/R) follicular lymphoma (FL): interim analysis of a phase Ib/I trial. J Clin Oncol. 2019;37(15_suppl):7505.

83. Salles G, Duell J, Gonzalez Barca E, Tournilhac O, Jurczak W, Liberati AM, et al. Tafasitamab plus lenalidomide in relapsed or refractory diffuse large B-cell lymphoma (L-MIND): a multicentre, prospective, single-arm, phase 2 study. Lancet Oncol. 2020;21(7):978-88.

84. Nattamai D, Neelapu SS. PD-1 expression is markedly upregulated on intratumoral CD4+ and CD8 + T cells in follicular lymphoma and is associated with T-cell exhaustion. Blood. 2007:1 10(11):2749.

85. Nastoupil L, Westin JR, Fowler NH, Fanale MA, Samaniego F, Oki Y, et al. High complete response rates with pembrolizumab in combination with rituximab in patients with relapsed follicular lymphoma: results of an open-label, phase II study. Blood. 2017;130(Supplement 1):414.

86. Armand P, Janssens A, Gritti G, Radford J, Timmerman J, Pinto A, et al. Efficacy and safety results from CheckMate 140, a phase 2 study of nivolumab for relapsed/refractory follicular lymphoma. Blood. 2021;137(5):637-45.

87. Armand P, Lesokhin A, Borrello I, Timmerman J, Gutierrez M, Zhu L, et al. A phase $1 \mathrm{~b}$ study of dual PD-1 and CTLA- 4 or KIR blockade in patients with relapsed/refractory lymphoid malignancies. Leukemia. 2021;35(3):777-86.

88. Ali K, Soond DR, Pineiro R, Hagemann T, Pearce W, Lim EL, et al. Inactivation of PI(3)K p1 10delta breaks regulatory T-cell-mediated immune tolerance to cancer. Nature. 2014;510(7505):407-11.

89. Vergadi E, leronymaki E, Lyroni K, Vaporidi K, Tsatsanis C. Akt signaling pathway in macrophage activation and M1/M2 polarization. J Immunol. 2017;198(3):1006-14.

90. Jaiswal S, Jamieson CH, Pang WW, Park CY, Chao MP, Majeti R, et al. CD47 is upregulated on circulating hematopoietic stem cells and leukemia cells to avoid phagocytosis. Cell. 2009;138(2):271-85.

91. Advani R, Flinn I, Popplewell L, Forero A, Bartlett NL, Ghosh N, et al. CD47 blockade by Hu5F9-G4 and rituximab in non-Hodgkin's lymphoma. N Engl J Med. 2018:379(18):1711-21.

92. Locke FL, Ghobadi A, Jacobson CA, Miklos DB, Lekakis LJ, Oluwole OO, et al. Long-term safety and activity of axicabtagene ciloleucel in refractory large B-cell lymphoma (ZUMA-1): a single-arm, multicentre, phase 1-2 trial. Lancet Oncol. 2019:20(1):31-42.

93. Jacobson C, Chavez JC, Sehgal AR, William BM, Munoz J, Salles G, et al. Primary analysis of Zuma-5: a phase 2 study of axicabtagene ciloleucel (Axi-Cel) in patients with relapsed/refractory (R/R) indolent non-Hodgkin lymphoma (iNHL). Blood. 2020;136(Supplement 1):40-1.

94. Fowler NH, Dickinson M, Dreyling M, Martinez-Lopez J, Kolstad A, Butler $J P$, et al. Efficacy and safety of tisagenlecleucel in adult patients with relapsed/refractory follicular lymphoma: interim analysis of the phase 2 elara trial. Blood. 2020;136(Supplement 1):1-3.

95. Goebeler ME, Bargou R. Blinatumomab: a CD19/CD3 bispecific T cell engager (BiTE) with unique anti-tumor efficacy. Leuk Lymphoma. 2016;57(5):1021-32.

96. Assouline SE, Kim WS, Sehn LH, Schuster SJ, Cheah CY, Nastoupil LJ, et al. Mosunetuzumab shows promising efficacy in patients with multiply relapsed follicular lymphoma: updated clinical experience from a phase i dose-escalation trial. Blood. 2020;136(Supplement 1):42-4.
97. Bannerji R, Allan JN, Arnason JE, Brown JR, Advani RH, Barnes JA, et al. Clinical activity of REGN1979, a bispecific human, Anti-CD20 x Anti-CD3 antibody, in patients with relapsed/refractory (R/R) B-cell non-Hodgkin lymphoma (B-NHL). Blood. 2019;134(Supplement_1):762.

98. Kim TM, Alonso A, Prince M, Taszner M, Cho S-G, Stevens DA, et al. A phase 2 study of odronextamab (REGN1979), a CD20 x CD3 bispecific antibody, in patients with relapsed/refractory B-cell non-Hodgkin lymphoma. Blood. 2020;136(Supplement 1):28-9.

99. Engelberts PJ, Hiemstra IH, de Jong B, Schuurhuis DH, Meesters J, Beltran Hernandez I, et al. DuoBody-CD3xCD20 induces potent T-cellmediated killing of malignant B cells in preclinical models and provides opportunities for subcutaneous dosing. EBioMedicine. 2020;52:102625.

100. Hutchings M, Mous R, Clausen MR, Johnson P, Linton KM, Chamuleau MED, et al. Subcutaneous epcoritamab induces complete responses with an encouraging safety profile across relapsed/refractory B-cell non-Hodgkin lymphoma subtypes, including patients with prior CAR-T therapy: updated dose escalation data. Blood. 2020;136(Supplement 1):45-6.

101. Bacac M, Colombetti S, Herter S, Sam J, Perro M, Chen S, et al. CD20-TCB with obinutuzumab pretreatment as next-generation treatment of hematologic malignancies. Clin Cancer Res. 2018;24(19):4785-97.

102. Casulo C, Byrtek M, Dawson KL, Zhou X, Farber CM, Flowers CR, et al. Early relapse of follicular lymphoma after rituximab plus cyclophosphamide, doxorubicin, vincristine, and prednisone defines patients at high risk for death: an analysis from the National LymphoCare Study. J Clin Oncol. 2015;33(23):2516-22.

103. Rummel MJ, Niederle N, Maschmeyer G, Banat GA, von Grunhagen U, Losem C, et al. Bendamustine plus rituximab versus $C$ HOP plus rituximab as first-line treatment for patients with indolent and mantle-cell lymphomas: an open-label, multicentre, randomised, phase 3 noninferiority trial. Lancet. 2013;381(9873):1203-10.

104. Morschhauser F, Fowler NH, Feugier P, Bouabdallah R, Tilly H, Palomba $\mathrm{ML}$, et al. Rituximab plus lenalidomide in advanced untreated follicular lymphoma. N Engl J Med. 2018;379(10):934-47.

105. Bachy E, Seymour JF, Feugier P, Offner F, Lopez-Guillermo A, Belada D, et al. Sustained progression-free survival benefit of rituximab maintenance in patients with follicular lymphoma: long-term results of the PRIMA Study. J Clin Oncol. 2019;37(31):2815-24.

106. Evens AM, Hong F, Habermann TM, Advani RH, Gascoyne RD, Witzig $\mathrm{TE}$, et al. A three-arm randomized phase ii study of bendamustine/ rituximab with bortezomib induction or lenalidomide continuation in untreated follicular lymphoma: ECOG-ACRIN E2408. Clin Cancer Res. 2020;26(17):4468-77.

107. Nastoupil L, Westin JR, Hagemeister FB, Lee HJ, Fayad L, Samaniego F, et al. Results of a phase II study of obinutuzumab in combination with lenalidomide in previously untreated, high tumor burden follicular lymphoma (FL). Blood. 2019;134(Supplement 1):125.

108. Hutchings M, Morschhauser F, lacoboni G, Carlo-Stella C, Offner FC, Sureda A, et al. Glofitamab, a novel, bivalent CD20-targeting T-cellengaging bispecific antibody, induces durable complete remissions in relapsed or refractory B-cell lymphoma: a phase I trial. J Clin Oncol. 2021. https://doi.org/10.1200/jco.20.03175.

\section{Publisher's Note}

Springer Nature remains neutral with regard to jurisdictional claims in published maps and institutional affiliations. 